\title{
Developmental Dyslexia and Specific Language Impairment: Same or Different?
}

\author{
Dorothy V. M. Bishop \\ Oxford University
}

\author{
Margaret J. Snowling \\ University of York
}

\begin{abstract}
Developmental dyslexia and specific language impairment (SLI) were for many years treated as distinct disorders but are now often regarded as different manifestations of the same underlying problem, differing only in severity or developmental stage. The merging of these categories has been motivated by the reconceptualization of dyslexia as a language disorder in which phonological processing is deficient. The authors argue that this focus underestimates the independent influence of semantic and syntactic deficits, which are widespread in SLI and which affect reading comprehension and impair attainment of fluent reading in adolescence. The authors suggest that 2 dimensions of impairment are needed to conceptualize the relationship between these disorders and to capture phenotypic features that are important for identifying neurobiologically and etiologically coherent subgroups.
\end{abstract}

Specific language impairment (SLI) and developmental dyslexia (also known as specific reading disability; SRD) are common developmental disorders that have a serious impact on a child's educational and psychosocial outcome. SLI affects around 3\%$10 \%$ of children (Tomblin et al., 1997) and is diagnosed when oral language lags behind other areas of development for no apparent reason (L. B. Leonard, 1998). Similar prevalence levels are reported for developmental dyslexia, which is identified if a child has poor literacy skills despite adequate intelligence and opportunity to learn (Snowling, 2000). In both SLI and dyslexia, the diagnostic criteria specify that the child has to have adequate hearing and no major handicapping condition that might interfere with learning. For many years, research on these two disorders followed separate paths, with the study of SLI being largely carried out by speech and language pathologists, whereas dyslexia was the focus of educators and psychologists. In the 1960s dyslexia was frequently conceptualized as a visual perceptual disorder. However, over the past 30 years, there has been a shift of emphasis, with growing recognition that most children with dyslexia have major difficulties in phonological processing, that is, categorizing speech sounds and relating these to orthography (Snowling, 1987; Vellutino, 1987).

In parallel with this work on dyslexia, a number of studies appeared that drew attention to problems with auditory perception

Dorothy V. M. Bishop, Department of Experimental Psychology, Oxford University, Oxford, United Kingdom. Margaret J. Snowling, Department of Psychology, University of York, York, United Kingdom.

Dorothy V. M. Bishop is supported by a Principal Research Fellowship from the Wellcome Trust. We thank Kate Nation, Charles Hulme, Courtenay Norbury, Julia Carroll, and Genevieve McArthur for helpful comments on this article.

Correspondence concerning this article should be addressed to Dorothy V. M. Bishop, Department of Experimental Psychology, Oxford University, South Parks Road, Oxford OX1 3UD, United Kingdom. E-mail: dorothy.bishop@psy.ox.ac.uk and phonological processing in SLI (Tallal \& Piercy, 1974; Tallal, Stark, Kallman, \& Mellits, 1980). Gradually, researchers began to question the sharp divide between dyslexia and SLI, with some suggesting that they were points on a continuum rather than distinct disorders (Kamhi \& Catts, 1986). As Catts (1991) put it, "Many cases of dyslexia are best characterised as instances of a developmental language disorder, a disorder that is present early in life and manifests itself in different ways during development" ( $p$. 164). As the 21 st century begins, this conceptualization of the two disorders has become so prevalent that it is common for authors of research reports to use new terms such as language learning impairment to encompass children with reading and/or oral language impairments (Tallal, Allard, Miller, \& Curtiss, 1997).

Our goal in this article is to examine the relationship between dyslexia and SLI to ask whether those working in the field should abandon the distinction between them or whether we need to retain some differentiation. We conclude that though there are close behavioral similarities between SLI and dyslexia, it is helpful to retain a distinction between relatively restricted problems with literacy and difficulties that encompass production and comprehension of spoken language. In the field of dyslexia, there has been an overwhelming emphasis on poor phonological processing as a cause of reading difficulties. However, study of children with oral language problems indicates that difficulties with semantics, syntax, and discourse will also affect literacy acquisition; in some children (so-called poor comprehenders) these difficulties may occur without any phonological impairment. In more classic cases of SLI, there can be both phonological and nonphonological language impairments that affect learning to read. Our working model (see Figure 1) shows dyslexia and SLI, not on a single continuum, but rather occupying different areas of a two-dimensional space. There are continuities, but the differences between subtypes of language-learning disability cannot be captured by a simple gradient of severity. Indeed, a full characterization of the varieties of difficulty is likely to need more dimensions than the two shown in Figure 1. 


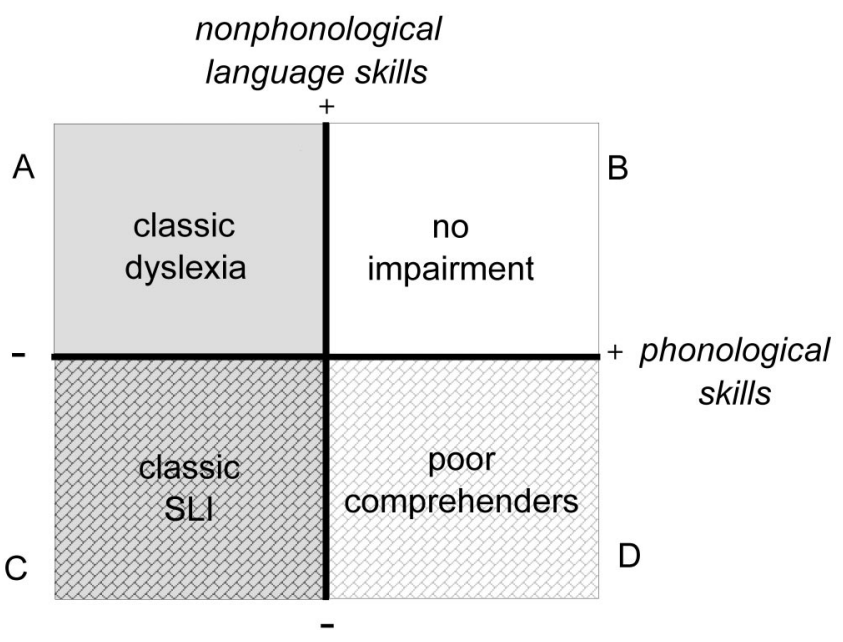

Figure 1. A two-dimensional model of the relationship between dyslexia and specific language impairment (SLI).

A second reason for resisting the tendency to merge dyslexia and SLI is that, as we shall see, disorders that appear similar at the behavioral level may have different causal origins. The causal model we adopt, illustrated in Figure 2, is heavily influenced by the work of Morton and Frith (1995) and Pennington (2002) and makes a distinction between observed behavior, cognitive processes, neurobiology, and etiology.

At the level of observed behavior one can ask whether children with a diagnosis of SLI have problems with skills such as reading and spelling and whether children with dyslexia have impairments on tests of oral language expression and comprehension. Overlap at the behavioral level, however, would not necessarily mean the disorders are qualitatively the same. Speaking, understanding, reading, and writing are complex processes, and impairment in these could reflect different underlying cognitive impairments. To assess cognitive impairment, researchers and practitioners need to move away from global measures of reading or language and use instead measures of underlying component processes. This may involve comparing reading or language behavior across different conditions (e.g., reading irregular vs. regular words; judging acceptability of sentences that contain grammatical vs. semantic violations), or measuring skills that appear to be implicated in reading or language but which do not require the testee to read or speak, such as tests of phonological awareness or auditory discrimination. Two children with the same behavioral impairment may present with different profiles of cognitive impairment. For instance, poor reading could reflect problems in segmenting the sounds in words, limitations of vocabulary that make it hard for the child to guess the identity of a novel word, or weak grammatical skills that limit the child's ability to use sentence context to help decode an irregularly spelled word.

It is also possible that two children with the same cognitive impairment will present with different profiles of reading or language impairment. This could depend on the other cognitive resources available to the child: For instance, poor phonological awareness may have more serious impact on literacy skills in a child of low IQ than in one of high ability. The language that is being learned also determines how a cognitive impairment presents. For example, tasks that require the segmentation of spoken words into phonemes are more difficult for readers of English than for readers of regular orthographies such as German (Goulandris, 2003). In a similar vein, the tendency to omit grammatical markers (e.g., third person singular $-\mathrm{s}$ as in "comes") is common among English-speaking children with SLI but far less pronounced in Italian, in which these markers are stressed (L. B. Leonard, 1998). Thus, the manifestations of a cognitive deficit (e.g., in phonological processing or grammatical morphology) can be influenced by the specific language that is learned. Furthermore, the surface manifestations of a cognitive impairment may change with remedial instruction. For instance, children with dyslexia may, through hard work and special education, learn to compensate for their difficulties, so that by adulthood they no longer appear to have a serious problem with reading (S. E. Shaywitz et al., 2003).

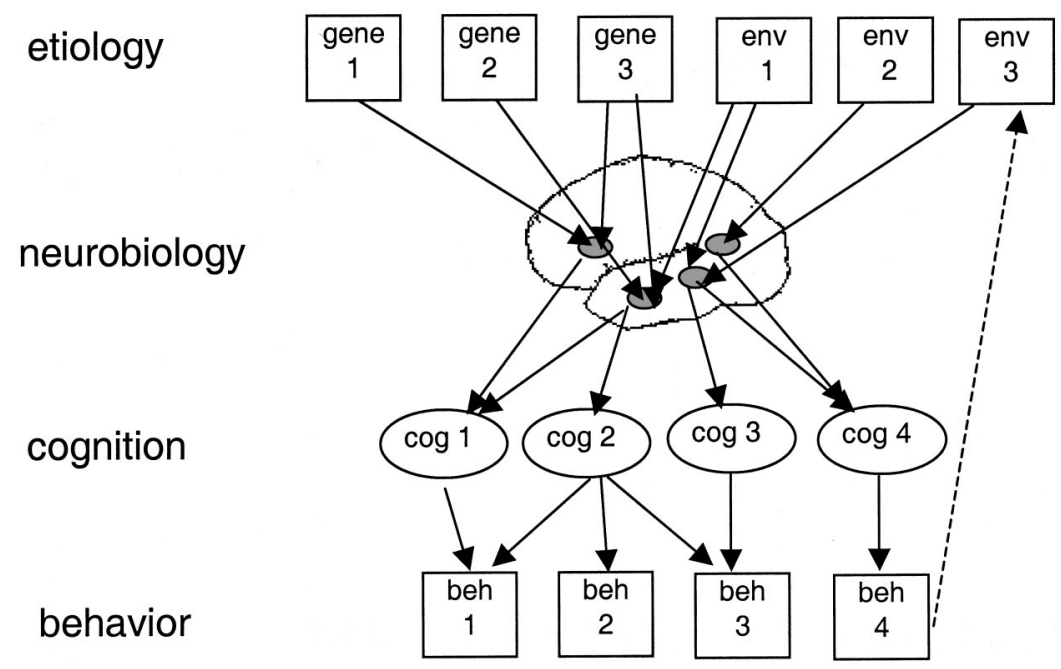

Figure 2. Levels of causation for developmental disorders. The dashed line emphasizes that children's behavior (beh) can affect the environment (env) they experience. cog $=$ cognition. 
N. E. Jackson and Coltheart (2001) have also stressed the need to distinguish between current cognitive deficits that explain a behavioral deficit (proximal causes) and those that operated in the past to lead to a current behavioral deficit (distal causes). For instance, as we discuss later, a child could have an auditory deficit early in life that subsequently resolves but has a long-lasting effect on the way in which phonological representations are set up. In such a case, an auditory deficit would be the distal cause of reading failure, but abnormal phonological representations would be the proximal cause.

The neurobiological level subsumes abnormalities of brain structure and function, and the etiological level encompasses both genetic and environmental factors that influence cognition via their effect on neurobiology. Environmental influences include remedial interventions that affect the brain and hence cognition (e.g., Richards et al., 2000). The dashed line from behavior to etiology in Figure 2 emphasizes that children's behavior can affect the environment they experience. For instance, children who are not motivated to read may fail to develop brain circuits for fluent reading even if books are present in the home because they do not engage in reading.

In asking whether SLI and dyslexia are the same disorder, one aim is to determine whether progress in understanding neurobiology and etiology will be advanced by collapsing the conditions together, keeping them separate, or adopting some other way of categorizing these disorders. However, it is important to recognize that paths from etiology to cognition via neurobiology are seldom simple, and one is unlikely to see one-to-one correspondences between etiology, neurobiology, and cognition. Disorders with relatively simple genetic bases are instructive here. For example, in tuberous sclerosis there is genetic heterogeneity; that is, the same phenotypic picture can be caused by mutations on either chromosome 9 or 16 (Udwin \& Dennis, 1995). The converse may also occur: The same genetic mutation may have different effects in different individuals - this may be because of interactions with other genes or with the environment. In some cases, variable expression of a genetic mutation is due to chance factors. The autosomal dominant disorder neurofibromatosis type I is a good example (Reiss \& Denckla, 1996): The same genetic mutation causes major brain abnormalities in some individuals and virtually none in others, leading to very different clinical pictures. This latter example illustrates that disorders that are etiologically the same could have distinct neurobiological bases and cognitive profiles.

In this article we start by highlighting some pertinent diagnostic issues. We then compare the behavioral manifestations of dyslexia and SLI before moving on to consider whether they have similar etiology or neurobiological origins. The remainder of the article then focuses on the underlying cognitive processes that mediate between the neurobiological and behavioral levels.

\section{Diagnostic Issues}

Clearly, whether we find similarities between dyslexia and SLI depends crucially on how they are defined. As shown in Figure 1, we regard it as important to establish whether a child with language or literacy problems has (a) problems with phonological processing and (b) problems with nonphonological language skills.
However, contemporary definitions of dyslexia and SLI tend to obscure this distinction.

\section{Definitions Based on IQ Discrepancy}

Many researchers adopt classic definitions of SLI and developmental dyslexia of the kind enshrined in the fourth edition of the Diagnostic and Statistical Manual of Mental Disorders (DSM-IV) diagnostic guidelines of the American Psychiatric Association (1994) or ICD-10 system of the World Health Organization (1993). These are referred to as discrepancy definitions because they embody the idea that a specific deficit (in language or in reading) occurs in the absence of poor general cognitive ability. In $D S M-I V$ and ICD-10, to meet diagnostic criteria, a person must show poor performance on a psychometric test of language or literacy and have a mismatch with a test of IQ. In the field of reading disability, there is a tradition of measuring degree of reading deficit in terms of the gap between "reading age" and chronological age. However, this has been largely superseded by reliance on standard scores, which represent the statistical abnormality of a person's deficit and avoid the psychometric pitfalls that are inherent in "age equivalent" scores (see Bishop, 1997, chap. 2). What ICD-10 and DSM-IV do not specify is which standardized tests of reading or language should be used, although this can make a crucial difference as to whether a child is identified as having an impairment. For instance, a test of reading accuracy will lead to different children being classified than a test of reading comprehension (Share \& Leikin, 2004). Likewise, the method used to assess IQ is important. In the case of SLI, it is usual to ensure that there is a mismatch between nonverbal intelligence and language skills. The situation is much less consistent in relation to developmental dyslexia, for which discrepancy definitions have been based on nonverbal (performance) IQ (e.g., Scarborough, 1990), verbal IQ (e.g., Snowling, Bishop, \& Stothard, 2000), and fullscale IQ (a composite of verbal and performance scales; Rutter \& Yule, 1970). Bishop and Butterworth (1980) noted that literacy scores are more strongly correlated with verbal IQ than nonverbal IQ. It follows that if dyslexia is defined in terms of reading score one standard deviation below nonverbal IQ, affected children will tend to have low verbal scores. If, on the other hand, verbal IQ is used, then far fewer children will be identified as having this degree of mismatch between IQ and literacy, and children with low verbal scores are likely to be excluded (see Figure 3).

\section{Alternatives to IQ Discrepancy Criteria}

Increasingly, theorists and clinicians have expressed dissatisfaction with approaches that incorporate IQ in the diagnostic criteria for developmental disorders (Lyon, 1995; S. E. Shaywitz, Escobar, Shaywitz, Fletcher, \& Makuch, 1992; Stanovich, 1994). As Stanovich (1986) pointed out with respect to dyslexia, verbal IQ may decline as a consequence of poor reading, a so-called Matthew effect, making it an unreliable standard against which to consider reading skills (B. A. Shaywitz et al., 1995). The use of performance IQ introduces different issues, not least that it is a poor correlate of reading and therefore not well justified as a predictor of expected reading attainment. Stanovich and Siegel (1994) compared IQ in children with specific reading difficulties (dyslexia) 

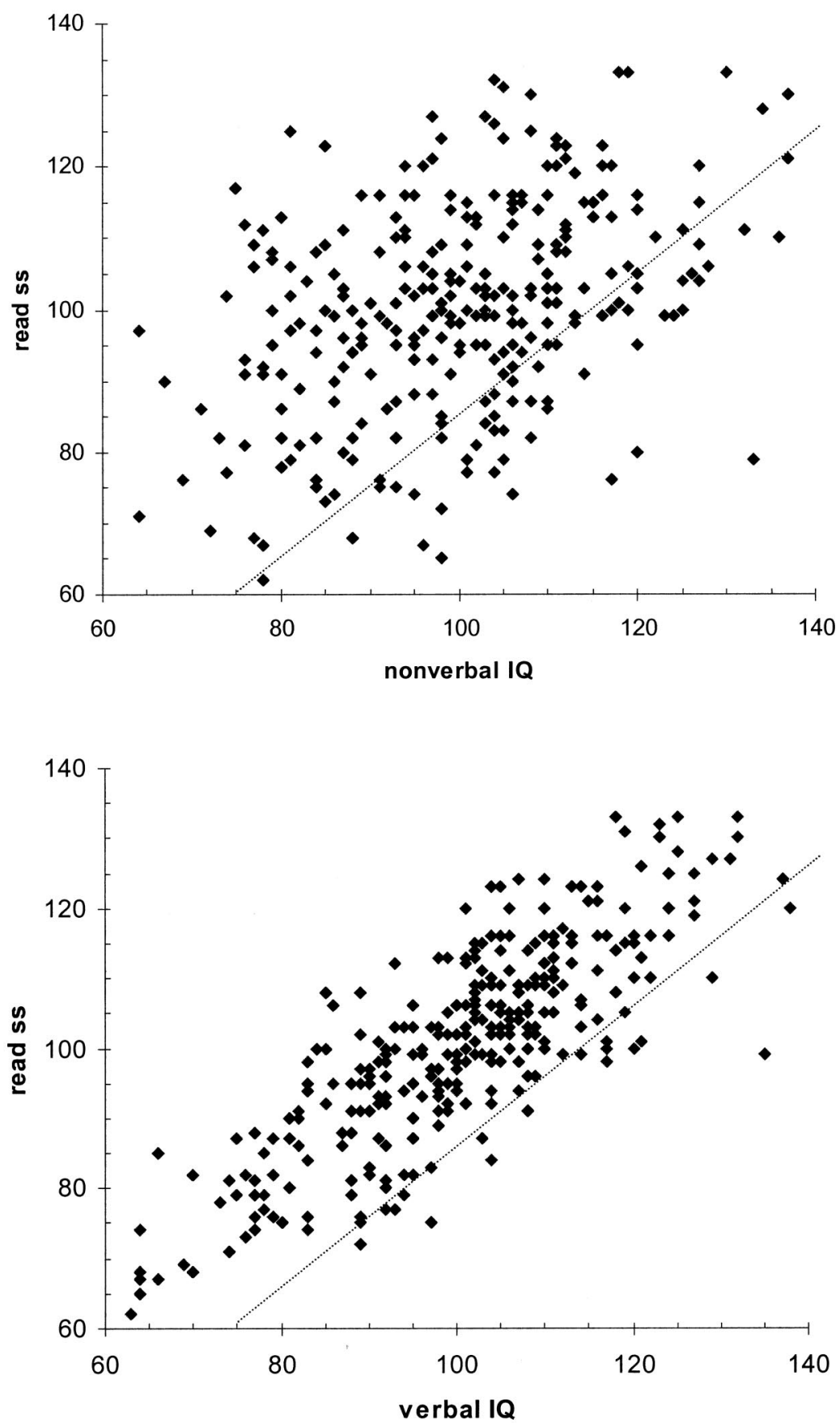

Figure 3. Scatter plots depicting relationship between nonverbal IQ and reading scaled score (read ss; $r=.40$; top graph) and verbal IQ and read ss $(r=.83$; bottom graph). Cases falling below the dotted line have a 15-point (1 SD) discrepancy between reading and IQ. Of the 57 discrepant cases in the top graph, 35\% have verbal IQ below 85 . Of the 16 discrepant cases in the bottom graph, $6 \%$ have verbal IQ below 85 . (For verbal and nonverbal IQ, $r=.42$.) Only 7 of the 57 cases who fall below the dotted line in the top graph also do so in the bottom graph.

and generally poor readers (referred to in this review as backward readers, though often referred to as garden-variety poor readers). They found that phonological skills rather than general cognitive abilities predicted reading attainment in both groups. A similar argument was adopted by Bishop (1994) when studying pairs of twins in which one member had SLI. Identical twins who were closely similar in their language impairments often had very different levels of nonverbal IQ. Hence, one twin would fulfill criteria for SLI and the other would not. When IQ was ignored, there was high heritability of language impairment, illustrating that differ- 
ences in IQ can potentially obscure similar etiologies of children with spuriously different diagnoses.

If IQ discrepancy criteria are abandoned, what should be put in their place? It is common to find researchers selecting children whose reading or language ability falls some way below age level, who have nonverbal IQ within broadly normal limits (e.g., Olson, Wise, Conners, Rack, \& Fulker, 1989; Tomblin, Records, \& Zhang, 1996; Vellutino, 1979). Note, however, that children selected in this fashion do not necessarily have a specific learning disability, in the sense that their language or literacy standard scores may co-occur with more global cognitive deficits.

In the more recent literature, it has become common to use even less stringent criteria, so that a child may be selected as "dyslexic" on the basis of having a nonverbal IQ within broadly normal limits and reading skills below the 25 th or 30 th percentile. Such diagnostic criteria will encompass a heterogeneous group of children, including some who would not normally attract clinical concern, others who have nonspecific reading difficulties, those who would fulfill ICD-10 diagnostic criteria for dyslexia, and some who would have clear-cut cases of SLI.

\section{The Cognitive Marker Approach to Diagnosis}

A much more radical, but to our minds preferable, approach is taken to the diagnosis of dyslexia by those who argue that affected individuals should be identified on the basis of the underlying cognitive deficit rather than observed behavior on psychometric tests (Frith, 1997; Snowling, 2000). Over the past 3 decades, so much evidence has accumulated for phonological deficits associated with dyslexia that Stanovich and Siegel (1994) proposed that dyslexia should be defined as a core phonological deficit (see also Snowling \& Hulme, 1994). The phonological deficit approach is commonly taken in studies of adults who may have overcome childhood difficulties to the extent of being able to read within normal limits but still show problems on tests of phonological processing (e.g., Paulesu et al., 1996). A similar approach has barely been applied in the study of SLI, although interest is developing in the idea of psycholinguistic markers that will be able to identify a distinct heritable subtype of disorder. For instance, Rice (2000) proposed that in heritable SLI there are distinctive problems in using verb inflectional endings.

Our view is that the cognitive marker approach is more likely to identify coherent groups of children than the traditional psychometric approach but that it is not sufficient to rely on a single dimension of impairment, such as phonological deficit. As we argue, it is important to distinguish children with relatively pure phonologically based reading problems from those with more global oral language impairments. In the longer term, good cognitive marker tests for the important aspects of language need to be developed, but meanwhile, one method to help distinguish cases in the different quadrants of Figure 1 would be to return to using a discrepancy measure-instead of having IQ as the baseline against which reading is assessed-to compare reading comprehension with listening comprehension (cf. Stanovich, 1994). This allows distinctions to be made between a child who has particular problems with written texts and one whose poor reading is but one manifestation of broader oral language problems.

\section{Subtypes of Developmental Disorder}

With respect to both SLI and dyslexia, there is a long history of attempts to classify affected children into different subtypes (Boder, 1973; Johnson \& Myklebust, 1967; Rapin \& Allen, 1983). In the field of reading disability, a distinction has been drawn between developmental phonological dyslexia, in which children read words significantly better than nonwords, and surface dyslexia, in which reading of regular words and nonwords is adequate but reading of irregularly spelled words is impaired. In the field of SLI, children can vary substantially in the severity of expressive and receptive language impairment and in whether their linguistic difficulties are compounded by nonorganic problems in speechsound production or problems with the pragmatics of language (Bishop, 2002c). A problem with all such taxonomies is that they leave some children unclassified and find few pure subtypes. Our view is that individual differences in reading and language disorders are better conceptualized in terms of a multidimensional model, in which there is continuous variation in component language and literacy skills, rather than discrete categories. In the model of Figure 1, we focus on two rather gross dimensions of impairment, but we anticipate that this is only a beginning and that these dimensions could be decomposed further as the understanding of cognitive underpinnings of language and literacy disorders develops.

We return to the issue of variation later in this review, in our discussion of ways in which reading development can be impaired. With the diagnostic issues that we have highlighted in mind, we now consider SLI and developmental dyslexia at the behavioral level of explanation before turning to the evidence concerning etiology, neurobiology, and cognitive processes.

\section{Observed Behavior}

At the behavioral level, we can ask, first, whether children with dyslexia have problems with oral language acquisition and second, whether children with SLI have problems with literacy skills.

\section{Oral Language Deficits in Children With Dyslexia}

More than 20 years ago, Vellutino (1979) reviewed the literature on dyslexia and concluded that reading disability was characterized by weaknesses in phonological, semantic, and syntactic processing and in verbal memory. More recently, McArthur, Hogben, Edwards, Heath, and Mengler (2000) used the Clinical Evaluation of Language Fundamentals-Revised (CELF-R; Semel, Wiig, \& Secord, 1987), a battery of oral language tasks that is widely used to diagnose SLI, with 110 children who had been identified as having SRD according to fairly standard psychometric criteriathat is, nonverbal IQ was within normal limits, and reading ability significantly below age level. Note that some subtests of the CELF-R present materials in written format and thereby handicap the child who has problems in reading. Nevertheless, it is unlikely that this could fully account for their finding that just over half of the SRD sample scored more than one standard deviation below the mean on the CELF-R. Even more striking are the findings of Stark and Tallal (1988), who selected a reading disabled group with the aim of excluding children with significant oral language difficulties. They required that children have an overall language 
age no more than 6 months below chronological age or performance mental age. Many potential participants were excluded from the SRD sample because their language skills fell below this level. The remaining children in the SRD group had oral language scores within normal limits, but scored significantly below control levels on expressive and receptive measures. The authors concluded that "the vast majority of children with reading impairment may also have some degree of oral language deficit" (Stark \& Tallal, 1988, p. 158).

\section{Could Poor Language Be a Consequence of Poor Reading in Dyslexia?}

If deficient oral language skills are found in poor readers, this raises questions about direction of causation. Similarities to SLI could be entirely superficial if the language limitations in dyslexia are simply the consequence of limited exposure to written materials, which could, for instance, depress vocabulary. Such a negative Matthew effect has been hypothesized for poor readers by a number of authors (B. A. Shaywitz et al., 1995; Stanovich, 1986) and received direct support from a longitudinal study conducted by Share and Silva (1987), which documented a significant decline in the language skills of reading disabled children between 3 and 11 years of age. Vellutino, Scanlon, and Spearing (1995) provided further evidence that semantic deficits become more of a problem as development proceeds by showing that fifth-grade children with reading disability had more pervasive semantic deficits than second graders. Overall, then, there is some support for the idea that poor reading can depress oral language skills. But is this the whole explanation for the verbal deficits in dyslexia?

The best way to demonstrate that oral language deficits in dyslexia were not simply a consequence of poor reading would be to demonstrate such deficits in young children before they had started to read. Most of the early data on this question focused on acquisition of language milestones, with consensus emerging that language delay was more frequent in children with dyslexia than in matched control children (Naidoo, 1972; Rutter \& Yule, 1970). However, these studies had the drawback that they relied on parental memories of early development, which may be skewed by a parent's awareness of a child's difficulties. This limitation is overcome by prospective studies of children who are at a high risk of dyslexia because of a positive family history. By recruiting offspring of parents with dyslexia, one has a good chance of finding a significant number of children who turn out to have reading problems (Elbro, Borstrom, \& Petersen, 1998; Pennington \& Lefly, 2001; Scarborough, 1990; Snowling, Gallagher, \& Frith, 2003) and can examine them from an early age, well before they are taught to read.

In general, such high-risk studies have provided strong evidence for continuities between oral and written language difficulties in that they reliably find that language development of children from at-risk families is slow in the preschool years (Byrne, FieldingBarnsley, Ashley, \& Larsen, 1997; Gallagher, Frith, \& Snowling, 2000; Lefly \& Pennington 1996; Locke et al., 1997; Lyytinen, Poikkeus, Laakso, Eklund, \& Lyytinen, 2001).

Scarborough and Dobrich (1990) studied 3 high-risk children who had early language delay (no word combinations at 30 months of age) and showed that their problems became milder and more selective as they grew older. However, when they entered Grade 2, all 3 had severe reading disability. On the basis of these data, Scarborough and Dobrich proposed a model of illusory recovery, illustrated in Figure 4. According to this model, oral language develops rapidly in the first 3-4 years of life and then reaches a plateau toward the end of the preschool period. At around 5-6 years of age, the child is exposed to literacy and normally starts to make rapid progress in reading and writing. However, suppose a common process important for both oral and written language development is impaired in some children. One might then see a delay in early oral language acquisition, followed by a period of apparent catch-up (illusory recovery) as normal development starts to plateau, with a subsequent deficit in mastery of literacy skills.

$$
\text { - - - typically developing —— late developing }
$$

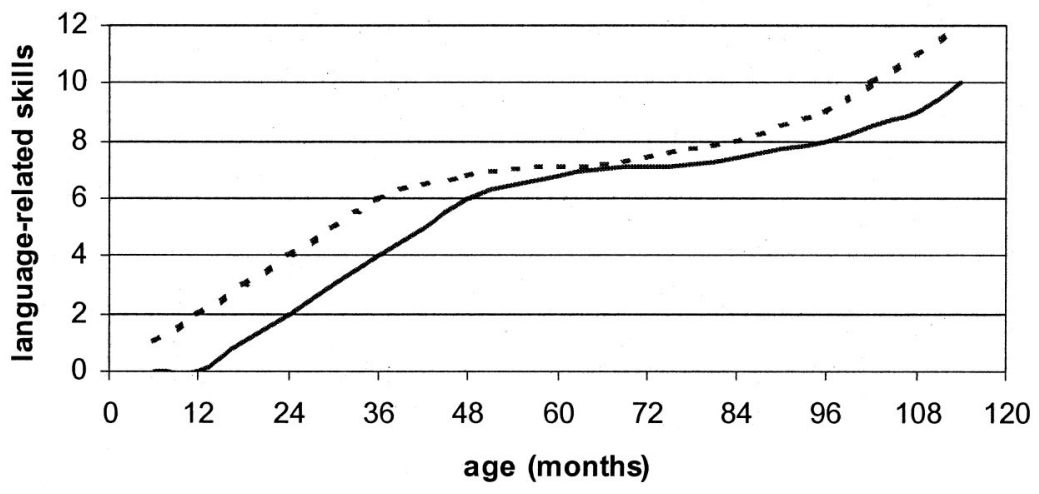

Figure 4. Scarborough and Dobrich's (1990) model of illusory recovery. The growth curve for the late developing group is identical in form to that for the typically developing group, but delayed by 12 months. The language-related skills scale on the $y$ axis is a theoretical construct that encompasses both oral and written language attainments. Adapted from "Development of Children With Early Language Delay," by H. S. Scarborough and W. Dobrich, 1990, Journal of Speech and Hearing Research, 33, p. 70. Copyright 1990 by the American Speech and Hearing Association. Adapted with permission. 
The illusory recovery model regards language impairment and dyslexia as different manifestations of the same underlying disorder: Age determines whether oral or written language problems are more apparent.

\section{Literacy Problems in Children With SLI}

If the early oral language deficits in dyslexia are causally linked to the literacy problems, then one should expect to find high rates of literacy problems in children who present with SLI. This is indeed the case. In a survey of children attending a school that specialized in the education of children with SLI, Haynes and Naidoo (1991) reported that only 7 of 82 children were free of reading problems. On leaving school, with a mean age of 11.5 years, the mean reading age was 8.5 years, despite intensive intervention. Tallal et al. (1997) followed up 67 children diagnosed with SLI at 4 years of age and compared their academic outcomes with 54 control children who were matched in terms of initial nonverbal ability. The mean scores for the SLI group on tests of decoding, reading vocabulary, reading comprehension, and spelling at 8 years of age ranged from 0.7 to 1.1 standard deviation below the control mean. Conti-Ramsden, Botting, Simkin, and Knox (2001) studied 11-year-olds with SLI and showed that $77 \%$ scored more than 1.0 standard deviation below age level on singleword reading, and $98 \%$ scored this poorly on a test of reading comprehension. Such evidence converges with a large literature investigating both the relatively short-term (e.g., Aram \& Nation, 1980; Stark et al., 1984) and the longer term consequences of language impairment (e.g., Aram, Ekelman, \& Nation, 1984; Felsenfeld, Broen, \& McGue, 1992; King, Jones, \& Lasky, 1982; Tomblin, Freese, \& Records, 1992), showing that oral language difficulties during childhood place children at risk of literacy problems (Bird, Bishop, \& Freeman, 1995; Bishop \& Adams, 1990; Catts, 1993; Catts, Fey, Tomblin, \& Zhang, 2002; Magnusson \& Naucler, 1990; Snowling et al., 2000).

As we have noted above, the diagnostic category of SLI embraces a wide range of difficulties, raising the question of whether literacy problems are linked to particular aspects of language difficulty. Of particular interest are longitudinal studies that follow the progress of preschoolers with SLI as they learn to read. Such studies can indicate which aspects of early language difficulty are most closely predictive of later literacy skill. As there is good convergence between studies in this area, we present a selective review of some of the larger scale studies that adopted a range of language and literacy measures. The results support the idea that oral and written language problems go hand in hand, but they also reveal some surprises. First, oral language problems are at least as strongly linked to poor reading comprehension as to decoding skills. Second, overt problems with speech-sound production, which might be expected to pose a serious risk for the development of letter-sound decoding skills, do not usually lead to literacy problems unless they are severe and persistent or accompanied by other language difficulties.

Literacy outcomes in preschool children with oral language impairments. The relationship between language and literacy problems was the focus of an epidemiological study by Catts et al. (2002) of the reading outcomes in second and fourth grade of 328 kindergartners with language impairments. At each time point, the children were assessed on tests of phonological awareness, rapid naming, letter identification, word identification, word attack, and reading comprehension skills. Children with resolved language impairment had a better outcome than those with persistent difficulties (although they still performed less well than controls). A noteworthy feature of this study was the finding that both reading comprehension and reading accuracy were impaired: That is, SLI was associated with problems in understanding written language as well as in decoding print. Concurrent language skills accounted for around one tenth of the variance in reading comprehension skills. Once word-level reading skill was controlled, second-grade grammar accounted for a unique $3.7 \%$ of the variance in reading comprehension in fourth grade, and phonological awareness for a unique $1.2 \%$ of variance in word recognition.

Rather similar findings were obtained by Bishop and Adams (1990), who followed a clinical sample of children with SLI from 4 years of age until 8 years of age. For many of these preschool children, the spoken language difficulties had resolved by 5.5 years, and this subgroup appeared to show normal reading accuracy, reading comprehension, and spelling at 8.5 years. They also performed as well as age-matched controls on tests of nonword reading and spelling, indicating that their experience of printed words was generalizing normally to the processing of novel items. In contrast, children who had persistent and specific language impairments at 5.5 years had widespread reading and spelling difficulties, and a relatively high proportion of them had particularly poor reading comprehension scores in relation to nonverbal IQ.

Stothard, Snowling, Bishop, Chipchase, and Kaplan (1998) reassessed this cohort at 15 years of age. In the SLI group as a whole, there had been a substantial drop in reading accuracy relative to age between the ages of 8 and 15 years (Snowling et al., 2000). Whereas the most marked difficulties observed earlier in development were problems of reading comprehension, now word recognition and decoding deficits were evident. It is plausible, given present understanding of how children read new printed words (Share, 1995, 1999), that children with language difficulties are vulnerable to literacy impairments for at least two reasons. First, and most widely acknowledged, children with SLI have difficulties with phonological analysis and memory. At 8.5 years, children with "resolved" SLI had been able to read and spell nonwords normally, but this was no longer the case at 15 years. At the later time point, the nonword reading test comprised multisyllabic words, and the SLI group's phonological skills were insufficient to allow success. Second, to the extent that children can use sentence contexts to boost their reading of new words (Adams, 1990), children with language difficulties will experience slow growth of a sight vocabulary. Weak ability to use contextual bootstrapping is likely to have a particularly deleterious effect on children learning to read in an orthography that contains many irregular words that cannot be deciphered using phonological rules (cf. Nation \& Snowling, 1998a).

Expressive phonology. The term expressive phonological impairment is used when children have difficulties with speechoutput processes (Dodd, 1995; Stackhouse \& Snowling, 1992). These children make frequent errors of pronunciation, and their speech can be difficult to understand. In the past the term functional articulation impairment was often used, and terms such as speech impairment or speech sound disorder are still commonly adopted when describing such children. In this article, we use 
whichever terminology was adopted in a given study. Note that in the studies we review, the terms speech or articulation impairment apply exclusively to difficulties that have no physical basis. Problems with expressive phonology are frequently seen in children with SLI, though they can occur as relatively isolated impairments in children with otherwise intact oral language. The extent to which reading problems can be traced to deficits in phonological skills, rather than to broader language impairments that frequently accompany these, is of considerable relevance for clarifying the relationship between dyslexia and SLI.

One might imagine that mapping between phonology and orthography would be particularly problematic if a child was not able to produce speech sounds accurately. However, studies of children with speech difficulties lead to the surprising conclusion that, provided the speech problem is not accompanied by broader language difficulties, it need not put a child at risk for reading problems, especially if the speech problem resolves before the child starts literacy instruction.

In the study by Bishop and Adams (1990) there were 12 children who had isolated phonological impairments affecting expressive phonology (speech) at 4 years of age. When the children were 8.5 years old, all but 1 had normal literacy skills for their age, and in adolescence, when 10 were available for retest, none had specific reading difficulties, though 1 had spelling problems (Snowling et al., 2000). Similar findings were presented by Catts (1991, 1993), who followed children with speech-language impairments from kindergarten to second grade. Children with speech-articulation difficulties in kindergarten did not develop reading difficulties in first grade, whereas those with more widespread language impairments did. However, children classified as speech and language impaired in case-control studies tend to have more severe speech difficulties than those with isolated speech impairments. It is therefore difficult to disentangle the effects of poor speech from those of poor language.

A rather different pattern of results was obtained by Bird et al. (1995), who followed 31 five-year-old children classified into those with and without additional language impairment. Children with speech difficulties had deficits on phonological awareness tasks at 6 and 7 years, and the majority displayed literacy problems at 7 years relative to controls matched for nonverbal ability. In this study, the presence of additional language difficulties did not significantly affect children's literacy outcome.

Possible explanations for the variability in outcome of children with speech difficulties are differences in the nature, severity, or persistence of the speech problems they exhibit (Raitano, Pennington, Tunick, Boada, \& Shriberg, 2004). Dodd (1995) reported that children who make consistently deviant speech errors are more likely to experience difficulties with phonological awareness and literacy development than those who make speech errors indicative of phonological delay, though it is important to note that IQ was not controlled in this study, nor in a replication by Leitão, Hogben, and Fletcher (1997). Another possible distinction is between children with specific difficulties in speech production and those whose speech problems affected input phonological processes (auditory and speech perception) as well as output processes (Stackhouse \& Snowling, 1992). A further possibility, proposed by Bishop and Adams (1990), is that, irrespective of whether the child has a specific speech problem or has speech and language difficulties, it is his or her phonological processing skills at the begin- nings of reading development (around 5 years of age in the United Kingdom) that will determine the child's ability to learn to read and spell.

Nathan, Stackhouse, Goulandris, and Snowling (2004) tested this critical age hypothesis in a longitudinal study of 47 children with expressive speech impairments studied from the age of 4.06 to 6.07 years, all of normal nonverbal ability. The children were classified into two subgroups at the start of the study, one with speech-only difficulties and one with additional language problems. Two years later, the speech-only group performed as well as IQ-matched controls on measures of phonological awareness, reading, and spelling ability, whereas the children with speech and language difficulties were impaired in phoneme awareness and showed a trend for their reading and spelling skills to be poorer. A second analysis looked at the reading-related skills of 19 children from the clinical sample who, at the age of 6.07, had persisting speech impairments. The performance of this group of children was worse on tests of reading, spelling, and phonological awareness than controls matched for age and nonverbal ability, in line with the critical age hypothesis. However, on average, these children also had poorer scores on tests of receptive and expressive language abilities.

The picture that emerges from studies of children with expressive phonological impairments is that language skills are stronger predictors of reading outcome than speech skills. However, there is clearly a significant amount of shared variance between speech and language processes (Carroll, Snowling, Hulme, \& Stevenson, 2003) and, depending on the make-up of clinical samples and the age at which they are tested, a significant role for speech-based processes may be revealed (Larrivee \& Catts, 1999).

\section{Overview}

This overview of behavioral data suggests that if one uses an operational definition of dyslexia that simply requires that the child have poor reading ability in the context of broadly normal nonverbal IQ, a high proportion of these cases will have impairments in oral language. Although some verbal deficit may be the consequence of poor literacy, high-risk studies show that language impairment is present in children with dyslexia even before they start to read. Looking at the issue from the opposite perspective most children who meet diagnostic criteria for SLI (poor oral language skills but normal nonverbal ability) would also meet psychometric criteria for SRD. It is this kind of evidence that leads some researchers to suggest that the difference between SLI and dyslexia is quantitative rather than qualitative. On this view, the specific diagnosis the child receives is a function of the age of the child, the severity of the impairment, and the professional discipline of the person making the diagnosis.

However, at the same time as people have become aware of commonalities between dyslexia and SLI, there has been growing consensus that neither disorder is homogeneous. Also, even though many children with dyslexia have oral language problems, a high proportion of them would not meet criteria for SLI because their oral problems are neither severe nor persistent. Furthermore, detailed analysis of literacy development in SLI shows some difference in the profile of literacy problems to that seen in classic dyslexia, with poor comprehension for written material a more prominent feature. This suggests the need for more than a single 
dimension of severity to capture the range of clinical variation. The two-dimensional model of Figure 1 posits commonalities between SLI and dyslexia in phonological deficits but also emphasizes that those with SLI have additional difficulties affecting other domains of oral language.

We discuss the nature of language problems in dyslexia, and literacy problems in SLI, in more detail in the Cognitive Processes section. First, however, we consider etiologic and neurobiological studies, some of which have raised questions about the wisdom of treating SLI and dyslexia together.

\section{Etiology}

\section{Genetics}

Aggregation in families. Both dyslexia and SLI tend to run in families (Flax et al., 2003; Hallgren, 1950). A question of considerable relevance for this review is whether relatives of people with dyslexia are at increased risk of SLI or vice versa. At first glance, the high-risk studies reviewed above seem to support the idea of a continuum between dyslexia and SLI because they demonstrate oral language deficits in children selected as being at genetic risk of reading disability. However, this may be less compelling than it appears, for two reasons. First, affected parents were typically identified on the basis of poor literacy skills, and in the absence of data on oral language, we cannot rule out the possibility that some of them had features of SLI. Second, although verbal development is often delayed in children at risk of dyslexia, it is seldom the case that these children are identified as having SLI and referred for intervention; for instance, only 1 child in the Snowling et al. (2003) study fulfilled diagnostic criteria for SLI.

Lewis (1992) addressed the question from the opposite perspective, considering whether rates of reading disability were increased in relatives of children with speech and language impairments. Probands (i.e., affected individuals who were the starting point for identifying families) had a history of moderate to severe preschool phonology disorder, with normal nonverbal IQ, in the absence of known causal factors. Just over half the probands also had broader difficulties with oral language. When compared with a matched control group, relatives of probands had significantly higher rates of speech-language impairment (13.6\% vs. $2.2 \%)$, dyslexia $(3.3 \%$ vs. $1.0 \%)$ and combined language-literacy problems (1.4\% vs. $0.1 \%)$. The findings in relatives were similar regardless of whether the proband's speech disorder was accompanied by more widespread language impairments. Lewis concluded that there may be a broad verbal trait that is heritable and deficient in affected families. The expression of this trait is variable and may be manifest as speech, language, and/or literacy problems. These results, then, are compatible with the view that language and literacy problems (and also nonorganic speech impairments) are on a continuum.

Flax et al. (2003) obtained a somewhat different pattern of results. They contrasted two groups of families. The first group, index families, all had a family member who met criteria for language impairment. The second group, control families, did not have an affected family member. In two studies they found that not only were the rates of language impairment much higher in index families than in control families, but reading impairments were also common. In contrast to Lewis (1992), most index relatives who had reading impairments also had language impairments. In the case-control study of Flax et al., 26\% of first-degree relatives of affected children had both language and reading impairments, $7 \%$ had language impairments only, and $9 \%$ had reading impairments only. Note, though, that the criterion for language and reading impairment was a score more than one standard deviation below the normative mean on a standardized test, without taking IQ into consideration. Thus it remains unclear how many relatives would have met discrepancy-based criteria for dyslexia. Overall, these two pedigree studies are compatible with a model that treats dyslexia and SLI as different points on a continuum of severity of verbal deficit. The higher rate of deficits seen in index relatives in the Flax et al. study and the frequency of language-plus-literacy problems in these families could be accounted for by assuming that index probands in this study had a more severe underlying deficit than those in the Lewis study.

Family aggregation studies are compatible with a genetic etiology for both dyslexia and SLI, but they are not conclusive because family members share many environmental influences as well as genes. It could be the case, for instance, that low levels of literacy in parents increase the risk that their children will be poor readers because few books are available in the home. Family studies need to be supplemented with other methods to allow researchers to disentangle genetic and environmental influences.

Twin studies. Twin studies capitalize on the natural experiment provided by the existence of two types of twin who differ in their degree of genetic relationship: identical and nonidentical twins. By comparing twin-cotwin similarity for these two twin types, one can obtain an estimate of the importance of genetic variation in explaining behavioral differences. There have been only a handful of twin studies of SLI, but they all provide strong evidence for an important genetic contribution (see Bishop, 2002b, for review). Studies of reading disability are more numerous, and most find significant, though somewhat lower, heritability (see DeFries \& Alarcón, 1996, for review). In this context, it is surprising to find two British twin studies reporting that shared environment accounted for most of the variance in reading, once IQ had been controlled for (Bishop, 2001; Stevenson, Graham, Fredman, \& McLoughlin, 1987). Bishop (2001) discussed possible reasons for the differences between studies. Heritability is the proportion of variance attributable to genetic factors. This means that if there is substantial variance associated with environmental variation (e.g., if the quality of reading instruction varies widely within a sample) then heritability will be lower than if all children are exposed to a more uniform environment. Thus, one possibility is that the lower heritability estimates seen in the UK studies reflect more diverse educational experiences in these samples. In addition, both the Stevenson et al. (1987) and the Bishop (2001) samples were too small to provide a powerful estimate of heritability when the lowest $6.6 \%$ of the sample was selected as reading disabled, but in both studies the suggestion was that heritability was higher at this extreme level than when the poorest $16.0 \%$ of readers were included (see also Stevenson, 1991). This raises the possibility that genetic factors may be more important in causing severe reading disability than in cases of milder reading difficulties.

Another intriguing observation in Bishop's (2001) study, and subsequently replicated in a new sample by Bishop, Adams, and Norbury (2004), was that level of heritability depended on whether 
the child was impaired on a nonword repetition test. Nonword repetition, which is known to be a sensitive marker of SLI, is discussed more fully below (see Phonological memory). In brief, it is a test in which the testee is required to repeat back meaningless but pronounceable strings of syllables such as blonterstaping or perplisteronk. Poor readers with low nonword repetition scores had significantly higher heritability than poor readers who scored in the normal range on nonword repetition. This raises the possibility that genes may be implicated in causing literacy problems in only those reading disabled children who have weak skills in speech production or phonological short-term memory. In this regard, it is noteworthy that Raskind, Hsu, Berninger, Thomson, and Wijsman (2000) found that families containing a proband with dyslexia showed an aggregation pattern consistent with genetic influence on tests of nonword repetition and nonword reading but not on other language and literacy measures. Also of relevance is a twin study by Tunick and Pennington (2002) showing that a history of speech delay and developmental dyslexia were coheritable. Further, Snowling et al. (2003) reported that nonword repetition skills, rather than more general language abilities, were equally impaired in affected and unaffected children of families with a genetic risk of dyslexia. In a similar vein, Pennington and Lefly (2001) reported that the broader phenotype of dyslexia encompassed phonological short-term memory and rapid naming deficits.

Other studies support the idea that heritability varies according to how dyslexia is defined. Heritability seems highest when the focus is on classic dyslexia, in which phonological deficits are seen in a child of average IQ. Olson, Datta, and DeFries (1999) found that heritability estimates for reading comprehension were lower than estimates for word recognition, and the heritability estimates for word recognition were higher for probands with high IQ than for backward readers with lower IQ. Subsequently, Gayan and Olson (2001) used bivariate genetic analyses to estimate the degree of common genetic influence across literacy and phonological awareness skills in twins selected for poor reading ability. This method allows one to establish whether two heritable deficits are caused by the same genes or by different genes. Although phonological decoding and orthographic skills were both significantly heritable, there was only partial overlap between the genetic influences on these variables. Deficits in phonological decoding and poor phonological awareness had shared genetic origins, whereas the influences on orthographic deficits appeared to be largely independent of those on phonological awareness.

The notion that the genetics of dyslexia might depend on phenotype definition is an appealing one to those psychologists who have argued for different subtypes of reading disability. Castles, Datta, Gayan, and Olson (1999), for instance, made a distinction between phonological and surface forms of developmental dyslexia. They found that heritability was higher for poor readers who had a phonological dyslexic profile than for those with surface dyslexia. Shared environment appeared important in the etiology of surface dyslexia, consistent with claims that this reading profile may be more related to teaching method than to constitutional factors (Stanovich, Siegel, \& Gottardo, 1997).

Results like these suggest that more stringent criteria in selection of research participants may lead to more homogeneous results in genetic studies. It is not uncommon in contemporary studies to see included as "dyslexic" any child whose reading ability is below the 25th percentile, and whose nonverbal ability is within broadly normal limits. Bishop's (2001) study suggests that such a group will contain many children whose reading difficulties are predominantly environmental in origin, and their pattern of associated deficits may well be different from cases that would attract clinical concern.

Two behavior genetic studies have focused on heritability of perceptual deficits that have been mooted as causally implicated in dyslexia or SLI. Neither visual processing in dyslexia (Olson \& Datta, 2002) nor auditory processing in SLI (Bishop, Bishop, et al., 1999) was significantly heritable, even though the twin samples used in these studies showed strong heritability for literacy and language measures. Evidence such as this led Bishop, Bishop, et al. (1999) to propose that the perceptual deficits that often accompany language and literacy problems may be indicators of environmental risk factors that are neither necessary nor sufficient for the disorder to be manifest but which nevertheless can affect severity of impairment.

Molecular genetics. Findings of significant levels of heritability in developmental language and literacy disorders have stimulated a quest for the molecular basis of genetic influences. The past few years have seen some important developments in this area, but it is clear that the story is not going to be a simple one.

A major breakthrough came with the discovery of a specific point mutation in the KE family, a three-generational family in which half the members had a severe speech and language impairment. All affected individuals had the defective gene, whereas none of the unaffected individuals did. This discovery has potential to throw light on understanding how humans developed a language-specialized brain. However, it does not increase general understanding of the causes of SLI and dyslexia, because the mutation is not found in people unrelated to the KE family, regardless of whether they have SLI (Newbury et al., 2002). Furthermore, although both SLI and dyslexia aggregate in families, they typically do not show the clear-cut Mendelian pattern of inheritance that was seen in the KE family.

When searching for genes influencing SLI or dyslexia, researchers cannot simply compare affected and unaffected individuals on a gene-by-gene basis - there are far too many genes to consider, and many spurious associations would arise by chance. Linkage mapping capitalizes on the fact that there are regions of the genome that are highly polymorphic; that is, they vary substantially from one person to another. These regions are noncoding and therefore do not affect the phenotype, but they are inherited along with the rest of the DNA. Various kinds of research strategy are possible (Fisher \& DeFries, 2002): One can, for instance, take pairs of affected siblings and, using polymorphic markers, find regions of the genome that show linkage; that is, they were inherited from the same parent with above-chance frequency. In interpreting linkage analyses, it is important to be aware of two points. First, if we find linkage to a marker, this is not the same as finding a gene, but it narrows down the search for genes to those that are relatively close to the marker on the chromosome. Second, linkage is probabilistic. We do not expect to find one-to-one associations between markers and phenotypes because (a) the marker is not the same as a risk gene but is rather a stretch of DNA that tends to be inherited along with the gene and (b) most complex disorders depend on the combined influence of many genes of small effect, as well as environmental influences. 
In both SLI and dyslexia, linkage mapping and related methods have been used to identify several regions of the genome likely to contain genes associated with disorder. Fisher and DeFries (2002) reviewed studies of dyslexia, noting the strongest evidence for linkage is to a site on the short arm of chromosome 6, which has been found in several different samples. Other linkages that have replicated in at least some samples are on the short arms of chromosomes 2, 3, and 18 and on the long arm of chromosome 15. A candidate gene on chromosome 15 has recently been uncovered by studying a family in which dyslexia is found in all members who have a chromosomal translocation (the attachment of part of one chromosome onto another) affecting the $15 \mathrm{q} 21$ region (Taipale et al., 2003). Yet another linkage site, on the long arm of chromosome 13, was found by Bartlett et al. (2002) using a sample in which the probands were selected in terms of meeting criteria for SLI but relatives were classified according to whether their reading was discrepant with nonverbal ability. For SLI, linkages have been reported to sites on chromosomes 16 and 19 (SLI Consortium, 2002, 2004), when the phenotype was defined in terms of poor nonword repetition or poor expressive language, respectively.

It is noteworthy that there is no overlap between the linkages reported for SLI and dyslexia. Although this may seem to provide strong evidence that they are etiologically distinct, Fisher and DeFries (2002) sounded a note of caution. These authors noted some statistical pitfalls that arise when conducting genetic analyses with complex traits. They were concerned with claims that different components of dyslexia (e.g., phonological vs. orthographic processing) are influenced by different genes, but the arguments they advanced apply equally to the issue of whether dyslexia and SLI are genetically distinct.

Fisher and DeFries (2002) described the typical scenario in the field of dyslexia, where investigators use several measures of reading and related skills to characterize the phenotype, each selected to assess a different aspect of dyslexia. Typically, these measures are significantly, though imperfectly, intercorrelated. Linkage mapping is then conducted for each measure separately. Using this kind of approach, Grigorenko et al. (1997) reported different linkages for measures of phonological awareness (linked to chromosome 6) and single-word reading (linked to chromosome 15 ) in a sample of people with dyslexia. However, in a subsequent study with a larger sample, they confirmed the linkage to the chromosome 6 locus but found this was now stronger for singleword reading than for phonological awareness (Grigorenko, Wood, Meyer, \& Pauls, 2000). Such puzzling discrepancies are likely to reflect the statistical problems inherent in linkage analysis. Marlow et al. (2003) noted that findings of selective linkage to one measure may be artifacts that arise when many analyses are run with the same sample. Using a new data set and a multivariate analysis in which data from six measures were considered simultaneously, they showed that measures that had not reached statistical significance when considered independently could contribute significantly to linkage when considered in combination with other measures.

The message from the Marlow et al. (2003) article is clear: Because statistical adjustments are made for multiple tests, traditional linkage mapping has low power to detect weak associations. It is tempting to think, when we see linkage for one measure to one site and for another to a second site, that we have uncovered a neat one-to-one correspondence between genotype and phenotype.
However, if we combine data from several phenotypic measures, we obtain a more powerful analysis that takes into account covariance between measures; when Marlow et al. did this, suggestions of linkages specific to one component of reading disability evaporated. This analysis shows that we should adopt extreme caution in interpreting findings of different linkage for different phenotypes. In the context of this article, this means that we should not conclude from linkage studies that SLI and dyslexia are genetically distinct entities, even though there is, as yet, no reported overlap between linkage sites for the two disorders. We now need multivariate studies that adopt the analytic approach used by Marlow et al. to see whether linkage signals are stronger when language and literacy measures are considered in combination.

\section{Environmental Factors}

As far as SLI is concerned, although numerous factors have been mooted as possible causes, to date it has proved difficult to identify any environmental agent or experience that is a necessary and sufficient cause of this disorder. Language development appears to be remarkably robust in the face of lack of verbal stimulation by parents, neurological impairments associated with perinatal problems, and fluctuating hearing loss associated with middle ear disease (see Bishop, 1997, for review). This is not to imply that these factors have no impact on development but rather to say that the documented effects of verbal deprivation, mild-to-moderate hearing loss, and focal brain injury are usually relatively mild, not specific to verbal skills, and do not lead to a clinical picture resembling SLI. It is possible that such environmental factors may assume more importance if they occur in a child already at genetic risk of disorder, but such gene-environment interaction has yet to be empirically demonstrated.

The principal environmental influences linked to children's success or failure in reading are educational experiences and home environment. Traditional definitions of dyslexia explicitly exclude children whose reading failure is caused by "inadequate opportunity to learn," but it is not always clear how to interpret this. Comparisons of children from the same catchment area attending different schools have emphasized that schooling can make a substantial difference to reading achievement (Rutter \& Maughan, 2002). There is also ample evidence of effects of the home environment on children's literacy; these appear to be mediated by oral language skills and are therefore more likely to affect reading comprehension than reading accuracy (Whitehurst \& Lonigan, 1998). It should be noted, however, that this evidence is correlational, and it is hard to establish how much of this association reflects a direct influence of home environment on the child's learning and how much arises because parents who themselves have a genetic predisposition to literacy problems tend to have children with similar problems.

\section{Overview}

Both dyslexia and SLI are etiologically complex disorders with a strong genetic basis. Genetic influences on reading disability appear to be most marked for cases that involve phonological impairments, that are out of keeping with other cognitive skills, and that are relatively severe. There is good reason for treating separately the milder and less specific forms of reading disability, 
which may be more influenced by environment than genes. Given the phenotypic overlap between SLI and dyslexia, we might have expected to find genetic overlap as well. However, to date, although molecular genetic studies have found evidence of linkages for both dyslexia and SLI, these have involved different loci. We note that statistical limitations of the method mean that this negative result cannot be taken as evidence for separate genetic mechanisms. What are now needed are more studies in which oral language and literacy skills are both measured in the same individuals so that the extent to which they share etiological influences can be directly assessed. It is possible that a clearer picture of the etiological relationship between dyslexia and SLI will emerge with more refined measures of the phenotype. For instance, the behavioral evidence from twin studies raises the intriguing possibility that a heritable deficit in nonword repetition will be found to be implicated in both disorders.

\section{Neurobiology}

\section{Micro- and Macroscopic Studies of Brain Structure}

Although some earlier studies reported clear pathology on brain scan or postmortem analysis of brains of people with congenital language disorders (e.g., Caparulo et al., 1981; Dalby, 1977; Landau, Goldstein, \& Kleffner, 1960), the majority of children with specific language and literacy problems do not have any detectable neurological abnormality on gross inspection of the brain. It seems likely that high rates of abnormality remarked upon in some earlier studies were due to inclusion of children with low IQ, frank neurological abnormality, epilepsy, or complex behavioral disorders.

As long ago as 1943, Worster-Drought surmised that some forms of developmental language disorder arose when neural connections failed to develop normally, perhaps because of genetic influences. Over the past 2 decades advances in neuroimaging as well as postmortem studies have provided evidence that early neurodevelopmental abnormalities are indeed implicated. A neuropathological study by Galaburda, Sherman, Rosen, Aboitiz, and Geschwind (1985) described the brains of 4 individuals with lifelong reading disability, all of whom had cerebral dysplasias (areas containing disoriented large cells that disrupted the laminar structure of the cortex) and ectopias (nests of cells in unusual locations), with the left hemisphere typically more affected than the right. The study by Galaburda et al. has been highly influential, but it nevertheless demonstrates the confusion in diagnostic terminology in this field. Although this study is widely cited as providing evidence of neuropathological abnormalities in dyslexia, 3 of the 4 individuals had delays in oral language development, and at least 1 continued to have marked oral language difficulties in childhood. Since the 1985 report, additional postmortem cases of similar cytoarchitectonic anomalies have been reported by $\mathrm{Ga}-$ laburda and colleagues (see G. D. Rosen, Sherman, \& Galaburda, 1993), as well as a case of "developmental dysphasia" by Cohen, Campbell, and Yaghmai (1989).

The high-resolution brain imaging methods that became widely available in the 1980s provided a means of studying macroscopic brain structure in living individuals. In general, few gross abnormalities are observed, leading researchers to focus more on looking for abnormalities in the proportions of different brain regions (e.g., Jernigan, Hesselink, Sowell, \& Tallal, 1991) and in whitematter connectivity (Klingberg et al., 2000). Any attempt to integrate the findings from structural imaging studies of dyslexia and SLI is hampered by the fact that, even within each of these disorders, there is often inconsistency in findings from one study to the next. Thus, although several studies have found that dyslexia and SLI are associated with a reduction or reversal in morphological asymmetry of the planum temporale (Hynd, SemrudClikeman, Lorys, Novey, \& Eliopulos, 1990; Kushch et al., 1993; Plante, Swisher, Vance, \& Rapcsak, 1991; G. D. Rosen et al., 1993), others have failed to replicate this, sometimes even finding an enhancement of the normal leftward asymmetry (C. M. Leonard et al., 2002; Preis, Jaencke, Schittler, Huang, \& Steinmetz, 1998; Rumsey et al., 1997). Others report abnormal gyral development in frontal (Clark \& Plante, 1998) or temporal (T. Jackson \& Plante, 1996; C. M. Leonard et al., 1993) regions of people with language impairments, but these associations are weak and probabilistic at best. Subcortical abnormalities affecting the caudate nucleus have been reported in affected individuals from the three-generational KE family, who have a dominantly inherited form of SLI (Watkins et al., 2002), but these people are both phenotypically and genetically different from other cases of SLI, and it is unclear whether a similar neuroanatomical profile will be seen in more typical cases.

One reason for the confusing and contradictory pattern of results may be the inclusion of different types of language and literacy problem under the general headings of dyslexia and SLI. Tentative support for this view comes from two studies by C. M. Leonard and her colleagues, who have attempted to distinguish phenotypic subgroups of individuals with reading difficulties that have distinctive neuroanatomic correlates.

In a preliminary study, C. M. Leonard et al. (2001) used magnetic resonance imaging to examine structural brain characteristics of 13 reading disabled adults, who were compared with 15 matched controls. All 13 were certified as reading disabled, but their cognitive profiles were quite variable, and only 9 showed a selective impairment in phonological decoding. On post hoc analysis, this "phonological dyslexic" group looked very different from the remaining 4, who had generally weaker reading comprehension. C. M. Leonard et al. (2001) identified four "risk factors" that distinguished the people with phonological dyslexia: a marked rightward cerebral asymmetry, a leftward asymmetry of the anterior lobe of the cerebellum, a combined leftward asymmetry of the planum and posterior ascending ramus of the Sylvian fissure, and a large duplication of Heschl's gyrus on the left. Although none of these factors was found in all the cases of phonological dyslexia, when a risk index was computed on the basis of all four risk factors, this distinguished these people from the remaining participants. In contrast, the 4 people with poor comprehension were distinguished solely by low cerebral volume. C. M. Leonard et al (2001) were cautious in their interpretation of these results, which emerged in a post hoc analysis of the data, but they noted that a finding of small cerebral volume had also been found in the cases of SLI described by Jernigan et al. (1991).

C. M. Leonard et al. (2002) went on to see whether the same four characteristics that distinguished the two types of dyslexia in the 2001 study would also distinguish children with dyslexia from those with SLI. This was not the case: The four brain indices did not successfully predict the diagnostic group for 14 children with 
SRD and 21 with SLI. However, they did uncover three other features on which the SRD and SLI groups differed: normalized cerebral volume, surface area of left Heschl's gyrus, and planum temporale asymmetry (larger on the left for those with SRD, but symmetric for those with SLI). Returning to the adults in the original 2001 study, C. M. Leonard et al. (2002) showed that when all seven brain indices were used together, they successfully classified the 9 adults with phonological dyslexia together with the children with SRD, and the 4 with weak reading comprehension with the children with SLI. Finally, C. M. Leonard et al. (2002) used the same set of anatomical risk factors with a group of 103 unselected children. They found that the profile of phonological decoding and reading comprehension in these children was in line with expectation, so that those with a combined anatomical risk score in the phonological dyslexic region had poor scores on nonword reading, those with a combined score in the SLI region had poor reading comprehension, and those whose anatomical risk score was not at either extreme had the best overall scores on language and literacy.

Bishop (2002a) suggested that other features of the phenotype may be important in defining anatomically distinct subtypes. There is, for instance, debate as to how far dyslexia can be viewed as involving cerebellar dysfunction (Fawcett, Nicolson, \& Maclagan, 2001; Nicolson, Fawcett, \& Dean, 2001; Ramus et al., 2003; Van Daal \& Van der Leij, 1999; Wimmer, Mayringer, \& Landerl, 1998). Other studies of dyslexia and SLI have suggested that subtle motor difficulties may be seen as part of the phenotype of a heritable form of disorder (Bishop, 2002b; Viholainen, Ahonen, Cantell, Lyytinen, \& Lyytinen, 2002; Wolff, 1999). Such findings suggest that an index of motor skills may prove useful in identifying a distinct subgroup whose language or literacy problems are associated with cerebellar dysfunction. However, contrary evidence was provided by Eckert et al. (2003), who reported low volume of the right anterior lobe of cerebellum in children with dyslexia who were free of language and motor deficits. More research is required on the role of the cerebellum in relation to language to allow for more refined hypotheses about the neurobiology of disorders such as dyslexia and SLI.

\section{Functional Imaging}

Methods such as functional magnetic resonance imaging (fMRI) and positron emission tomography (PET) have the potential to reveal functional abnormalities in the brains of affected children. Temple (2002) reviewed studies that used PET or fMRI to investigate phonological processing and reading in people with dyslexia. Most of these studies have been conducted with adults, though Temple et al. (2001) showed that results obtained with adults generalized to a group of children. Temple (2002) noted that there was striking consistency across studies, despite differences in imaging procedures and test methods; people with dyslexia showed less activity than controls in the left hemisphere temporoparietal cortex (e.g., Paulesu et al., 1996). Few functional imaging studies have been done with children with SLI, but it is noteworthy that one study that looked at resting levels of brain activation also revealed abnormal function of the left temporoparietal region (Denays et al., 1989).

However, not all findings of functional abnormality throw light on the neurobiological origins of impairment-cause and effect can be difficult to disentangle. It is customary to assume that neurobiological factors influence cognition and behavior, but as illustrated in Figure 2, the causation can also go in the other direction. For instance, several recent studies have used fMRI to compare children with dyslexia and control children to look at how the brain responds as the participant silently reads real words or nonwords (e.g., Georgiewa et al., 2002; B. A. Shaywitz et al., 2002). Typically children with dyslexia find it much harder to read these materials than do control children, making it hard to know whether differences in brain activation are a sign of some constitutional limitation of brain processing or whether they simply reflect a person's ability to do the task. To take an extreme analogy, the brain of an English speaker would not be expected to show the same activation as a person fluent in Mandarin when confronted with Chinese orthography, yet one would not conclude that there was anything abnormal about the English participant's brain-just that it had a different experience in processing this kind of stimulus. One way of illuminating this issue would be to see whether the brain responses of control individuals would be influenced by giving them a much harder task, such as reading unfamiliar words or reading in a foreign language. Alternatively, a reading-level-matched control group of younger children could be used.

Functional imaging studies can be particularly useful, however, in testing theories of the underlying basis of dyslexia or SLI or in demonstrating abnormal localization of function or how the brain responds to intervention. As an example of the first kind of study, Temple et al. (2000) tested a theory that attributes dyslexia to low-level auditory problems in processing rapid stimuli. They reported that adults with dyslexia failed to show the usual differentiated brain response on fMRI for rapid versus slow temporal change in nonverbal auditory stimuli. This is a provocative finding, but it is hard to know how generalizable it is, and whether it applied only to poor readers with additional oral language deficits. Only a minority of people with dyslexia have problems in rapid auditory processing (Bailey \& Snowling, 2002; Ramus, 2003; S. Rosen, 2003), suggesting that participants in this study may have been atypical.

Analyses that consider correlations between activation in different brain regions have promise for throwing light on the relationship between language skills and dyslexia. S. E. Shaywitz et al. (2003) used this approach to study three groups of young adults from a prospective longitudinal study: people who had had longstanding reading problems since childhood (persistent poor readers), those whose childhood reading problems had resolved (compensated poor readers), and normal readers. Although persistent poor readers activated posterior reading circuits to the same extent as the control group, the pattern of correlated activations suggested that they did not show normal connectivity between these regions and frontal language areas. In contrast, the compensated poor readers showed relative underactivation in reading circuits in the left hemisphere and appeared to be using alternative circuits in the right hemisphere.

\section{Overview}

There is broad agreement that both SLI and dyslexia are associated with abnormalities of early neurological development rather than lesions acquired early in life. It seems likely that genetic 
influences affect the timing of processes of early neural migration, leading to nonoptimal patterns of connectivity in the brain. Much of the focus in imaging studies has been on the frontal and temporal regions of the brain known to be involved in language processing, although more recently the cerebellum and subcortical regions have also come under scrutiny. Although there is impressive consistency in functional imaging studies of dyslexia and SLI, similarity at the neurobiological level could be as much a product of the reading impairment as an explanation of its cause (Merzenich, 2001). Furthermore, neurobiological studies of brain structure have, to date, achieved little consensus on which regions are affected, with few consistent findings from one study to the next. The work by C. M. Leonard and colleagues $(2001,2002)$ suggests that better conceptualization of the phenotype may lead to a clearer picture, with a different neurobiological profile in people with relatively pure phonological dyslexia and those with more widespread language difficulties incorporating both oral and written comprehension.

Overall, then, neurobiological studies contrast with behavioral studies in suggesting that rather than collapsing together the categories of SLI and dyslexia, we in the field should distinguish between relatively pure reading difficulties and those associated with broader language impairments. However, it is clear that we need to move from simple behavioral measures of reading and language ability to document the underlying cognitive processes in these disorders.

\section{Cognitive Processes}

We have focused so far on similarities between dyslexia and SLI in terms of behavioral manifestations and underlying causes at the etiological and biological level. Our review stresses that literacy development is at least as much of a problem in children with SLI as it is in dyslexia. Does that mean that the same cognitive deficits are responsible for the literacy problems in both populations? To address this question, we first review contemporary theories of reading in dyslexia and then consider how far the same theoretical account is adequate to explain literacy development in SLI. We conclude that, although children with SLI have many of the same phonological processing problems as are seen in dyslexia, they have additional deficits in the domains of semantics, syntax, and discourse, whose impact on literacy development is often underestimated because of a tendency to focus on reading of single words rather than connected text. We also note the existence of children in whom semantic deficits occur in the absence of phonological impairment, so-called poor comprehenders, whose reading profile differs sharply from that in classic dyslexia, yet who have some commonalities with SLI.

\section{Learning to Read: A Theoretical Framework}

There is considerable debate as to how best to model the cognitive processes involved in reading, with a major divide between those who advocate traditional rule-based "box and arrow" models, such as dual-route theory (N. E. Jackson \& Coltheart, 2001), and connectionist models (e.g., Seidenberg \& McClelland, 1989). Despite some important theoretical differences, virtually all psychological models of reading conceptualize learning to read as a process whereby the child develops a system of mappings between printed words (orthography), spoken words (phonology), and word meanings (semantics). All models must explain how a child develops expertise in letter-sound correspondences, making it possible to generate pronunciations of words that have not been encountered before. To explain reading in a nontransparent orthography such as English, a model must also account for recognition of exception words such as pint, broad, or yacht that contain highly irregular spelling-sound correspondences. In analyzing the nature of literacy problems in dyslexia and SLI, we take as our starting point a simple connectionist system based on Seidenberg and McClelland (1989), which involves a set of phonological, orthographic, and semantic representations that are fully interconnected and are modified by learning. Note, however, the choice of this specific model is not key to the arguments we develop: Virtually all models, connectionist or otherwise, make this distinction between domains and mappings between them. One reason we prefer a connectionist model is because it models the learning of reading as well as proficient reading performance, making it wellsuited to the study of development. In this model there is a division of labor between a phonological pathway that maps orthography to phonology and a semantic pathway with mappings between orthography, semantics, and phonology (Plaut, McClelland, Seidenberg, \& Patterson, 1996; see Figure 5). Before training the model, the network's resources are devoted to establishing connections between orthography and phonology (as envisaged for the early stages of learning to read). As training proceeds, however, the model starts to depend less on the mappings between orthography and phonology and more on the semantic pathway, which processes exception words with inconsistent mappings between letters and sounds more economically. Another reason for our favoring a connectionist approach is because, in line with data from children learning to read (e.g., Laing \& Hulme, 1999), it treats semantic and phonological domains as interactive rather than separate domains.

As we argue later, models of reading that focus on the decoding of single words, such as the triangle model, are an oversimplification, as they focus primarily on the mechanics of reading, and give less attention to the process of extracting meaning from print (i.e., reading comprehension). However, the bulk of research on dyslexia has focused on single-word reading, so we start by considering models that focus on this skill.

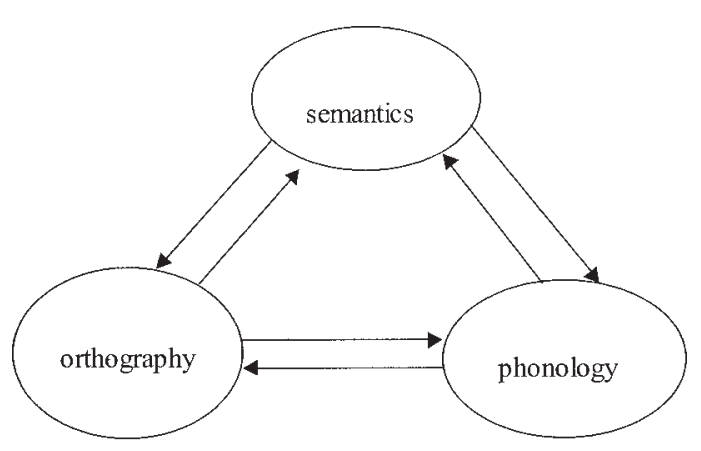

Figure 5. The triangle model described by Plaut, Seidenberg, McClelland, and Patterson (1996). Adapted from "A Distributed, Developmental Model of Word Recognition and Naming," by M. S. Seidenberg and J. L. McClelland, 1989, Psychological Review, 96, p. 526. Copyright 1989 by the American Psychological Association. 


\section{Reading in Dyslexia and SLI in the Context of the Triangle Model}

In principle, the source of a child's reading problem could be in any one of the kinds of representation depicted within the ovals shown in Figure 5, but in practice research has focused primarily on phonological deficits, and to a lesser extent on semantic impairments, as there is little evidence that orthographic impairments are the primary source of literacy problems in either SLI or dyslexia. A child who has imprecise representations at the phonological level will have difficulty establishing mappings between phonology and orthography because these depend on fine-grained connections (Harm \& Seidenberg, 1999; Plaut et al., 1996). The connections between phonology and semantics would be less compromised because mappings are between morphemic or wordbased units. On the other hand, imprecise semantic representations would not affect the phonological pathway (Plaut, 1997). The model also allows for the possibility that each kind of representation is intact, but there is difficulty in learning mappings between them. The development of mappings could be constrained for a number of reasons. Most straightforward would be a learning difficulty, implemented in the model by reducing the number of hidden units in the system or by changing the model's resources via adjustments to the learning parameter. Alternatively, memory limitations, which may be implemented in a connectionist framework as an unusually rapid decay of activation, would also be expected to affect rate of learning.

The connectionist perspective highlights the cognitive resources that are required to develop a competent word recognition system, though at this point we should note that it is silent as to the prerequisites of reading comprehension. The necessary resources include segmental phonological representations, ability to identify letter sequences, semantic knowledge, and adequate memory and learning resources. Note, however, that the bidirectional relationships between different components of the triangle model mean that we would not expect to find highly selective impairments in one aspect of the reading process. Although a cognitive deficit affecting one part of the system will lead to a distinctive profile of difficulty, it is likely to have an impact on the working of the model as a whole. For instance, although we suggest that orthographic difficulties are seldom the primary source of poor reading, children with weak phonological skills will do poorly on tests of orthographic processing because they have failed to develop appropriate mappings from phonology to orthography. We can now turn to consider what is known about these various skills in children with dyslexia and SLI.

\section{Profile of Reading Impairment in Dyslexia and SLI}

A time-honored method for studying underlying cognitive deficits is to compare ability to read different types of materials. Reading of nonwords, such as zost or trapedent, cannot be achieved by using semantics, and so must depend on mapping between orthography and phonology. Reading of orthographically irregular words is less straightforward, and it is generally accepted that at some level, reference to semantics is required; in the connectionist framework, the most efficient way of reading these words is using the semantic pathway. By comparing the reading profile of children with dyslexia with that of younger normal readers of the same overall reading level, one can gain insights into which aspect of reading is disrupted.

The most common pattern of reading deficit observed in dyslexia is poor nonword reading in the face of better developed word reading skills (Rack, Snowling, \& Olson, 1992), which, in terms of Figure 5, corresponds to a specific weakness in the mapping from orthography to phonology (Harm, McCandliss, \& Seidenberg, 2003). In contrast, most studies that have examined regular and exception word reading in dyslexia have revealed a pattern of performance that is normal for reading level (Metsala, Stanovich, \& Brown, 1998).

It would be wrong to suggest that this profile of phonological reading impairment is seen in all poor readers. One can, for instance, find children who are worse at reading irregular words than nonwords and who resemble adults with "surface dyslexia" (Castles \& Coltheart, 1993). Moreover, it would be misleading to imply a clean divide between subtypes of poor readers; most researchers accept that there is a range of variation in reading behavior rather than sharply delimited groups (Griffiths \& Snowling, 2002; Murphy \& Pollatsek, 1994; Seymour, 1986). Nevertheless, the phonological dyslexic subtype appears to be by far the most frequent when comparisons are made between children with dyslexia and reading-age-matched controls (Manis, Seidenberg, Doi, McBride-Chang, \& Petersen, 1996; Snowling, Goulandris, \& Defty, 1998), and several authors have reported difficulty in isolating the surface subtype (Stanovich et al., 1997 Williams, Stuart, Castles, \& McAnally, 2003).

We are not aware of any study that has attempted to classify a group of children with SLI in terms of the surface-phonological dyslexic distinction, though there is ample evidence that such children are usually very poor at reading nonwords as well as words (e.g., Bishop \& Adams, 1990; Briscoe, Bishop, \& Norbury, 2001; Snowling et al., 2000). Furthermore, analysis of spelling errors showed that when compared with younger normally developing children at a similar language level, children with SLI made a disproportionately large number of errors that were phonologically inaccurate but that they were not prone to make undue numbers of orthographically illegal errors (Bishop \& Clarkson, 2003).

\section{A Core Phonological Processing Deficit in Dyslexia and SLI?}

It is widely believed that impaired phonological processing is the key deficit in developmental dyslexia (Snowling, 2000). Indeed, it has been proposed more than once that dyslexia should be defined in terms of phonological deficit. Because phonological processing deficits are also common in SLI, this suggests continuity between the two disorders (Kamhi \& Catts, 1986).

The general term phonological processing is often used rather loosely to refer to a wide range of cognitive skills involving speech sounds, but to understand the role of phonology in reading, it is important to distinguish between different components of phonological processing. The notion that impaired phonology might cause literacy problems in dyslexia seems at first paradoxical because most children with dyslexia do not have any obvious difficulties with the production of speech sounds. And indeed, as we have already mentioned, children who do have relatively isolated problems with speech-sound production do not typically go 
on to have literacy problems. A popular current view is that reading difficulties arise when a child has difficulty in analyzing the speech sounds of which words are composed, that is, weak phonological awareness.

Phonological awareness. Research on typically developing children has made it clear that the ability to pronounce a word such as cat may involve different kinds of underlying representation. Very young children typically operate with unanalyzed syllables and would not, for instance, appreciate that cat and bat have sounds in common. As they grow older, children start to segment syllables into two components: (a) the initial consonant(s) and (b) the vowel and any following consonant(s). Such children would not yet be aware that cat and bit had a common final sound. Only after exposure to written language do most children learn to segment syllables at the level of the individual phoneme (e.g., appreciating that cat, tack, and act are all composed of the same set of phonological units).

Phonological awareness refers to the ability to compare, segment, and discriminate spoken words on the basis of their phonological structure. The kinds of task used to assess phonological awareness include identifying the number of syllables or phonemes in a word; identifying which word is "odd man out" on the basis of its initial, middle, or final sound; rhyme judgment; and rhyme generation. More complex tasks tapping phonological awareness that also place some demands on executive function and memory are those in which it is necessary to manipulate a word by deleting, adding, or transposing sounds; for example, in a Spoonerism task, the initial segments from two words are transposed, so that back door becomes dack boor.

There is a large body of work showing that preschool phonological awareness predicts individual differences in subsequent reading attainment, even when general cognitive ability is controlled (Bradley \& Bryant, 1983; Lundberg, Olofsson, \& Wall, 1980; Wagner, Torgesen, \& Rashotte, 1994). Byrne (1998) has argued that to acquire the alphabetic principle, children not only have to learn letter-sound associations but also have to understand the concept of phoneme invariance (that the phonemes of spoken words are the same regardless of the phonetic context in which they occur). Thus, phoneme awareness provides a necessary foundation for the development of decoding ability, together with letter-sound knowledge.

A complementary body of evidence shows that phonological awareness is impaired in dyslexia (see Snowling, 2000, for review). Deficits in phonological awareness have also been associated with reading failure in SLI (Bird et al., 1995; Briscoe et al., 2001; Catts \& Kamhi, 1999; Joffe, 1998; Leitão et al., 1997; Nathan et al., 2004; Snowling et al., 2000).

The numerous findings of poor phonological awareness in children with SLI and dyslexia have led to widespread acceptance of a model in which immature or abnormal phonological representations lead to difficulty in forming stable mappings between phonology and orthography. However, findings of poor phonological awareness in poor readers do not prove that the relation is causal; phoneme awareness can be influenced by exposure to literacy (Morais, Cary, Alegria, \& Bertelson, 1979), specifically, to alphabetic writing systems (Read, Zhang, Nie, \& Ding, 1986). Illiterate adults show poorer phonological awareness than literate adults, and many preschoolers do not grasp the idea of segmental phonological representations until they are introduced to print. The strong reciprocal relationship between phonological awareness and literacy has been particularly noticeable in cross-linguistic studies, which have shown that, shortly after children begin to read, performance on phoneme awareness tasks increases dramatically among readers of transparent languages (Cossu, Shankweiler, Liberman, Katz, \& Tola, 1988; De Jong \& Van der Leij, 1999; Durgunoglu \& Oney, 1999; Wimmer, Landerl, Linortner, \& Hummer, 1991), whereas the development of phoneme awareness is quite slow in readers of English who are exposed to an opaque orthography in which letter-sound correspondences are inconsistent. Within this view, phoneme awareness deficits in readers of English may be exaggerated by learning to read in a writing system that does not bootstrap such skills.

Another point of concern for a model that regards phonological awareness as key is that training in phonological awareness is not always an effective means of remediating dyslexia (Torgesen, 2000). We have seen children who, after much intervention, can unerringly state which sound goes with which letter; can segment words into sounds; and yet who still have tremendous difficulties in reading fluently.

Does this mean, then, that findings of poor phonological awareness in children with SLI or dyslexia are simply consequences of their weak literacy skills (cf. Castles \& Coltheart, 2004)? That seems to be too extreme a conclusion, not least because poor phonological awareness is a persistent marker of an underlying deficit in compensated dyslexics who can read adequately (see Frith, 1997). Nevertheless, we suggest that the overwhelming emphasis on phonological awareness in studies of reading disability may be misplaced and that factors other than segmentation may be implicated in the difficulties children have in mapping between orthography and phonology. In addition, poor phonological awareness in dyslexia and SLI does not necessarily mean they have the same underlying cognitive deficit; rather, it may just reflect the fact that literacy skills are poor in both.

Low-level auditory processing. The view that phonological awareness deficits are just secondary to poor literacy is strongly challenged by an influential theory that attributes oral language difficulties to a low-level problem in auditory processing. Although initially this theory was regarded as specific to SLI and not applicable to dyslexia (Stark \& Tallal, 1988), it is now used to explain reading as well as oral language difficulties. The proposal is that in both disorders, poor auditory temporal resolution leads to difficulty in forming segmental phonological representations (Tallal, 2000). A child with this problem can identify syllabic units but will have difficulty recognizing that the initial segment of cat, car, and comb is the same phoneme. This would lead to difficulty learning to read in an alphabetic language. In severe form, the impairment could lead to problems in learning vocabulary and syntax (i.e., SLI).

Tallal's initial work was carried out in the 1970s with children with SLI. In the Auditory Repetition Test the child is presented with high and low tones and learns to associate a different button press with each tone. Pairs of tones are then presented, and the task is to press the buttons that correspond to the tone sequence (highhigh, high-low, low-high, or low-low). Children with SLI did as well as control children when the interval between the tones was $250 \mathrm{~ms}$ or more but were impaired at shorter intertone intervals. In 1980, Tallal not only found a similar pattern in children with reading disability but also demonstrated a significant correlation 
between their performance on the items with rapid interstimulus intervals and ability to read nonwords. Thus the scene was set for an elegantly simple model that regarded both reading disability and SLI as the consequences of phonological impairments that arose because of a low-level auditory perceptual problem in the processing of brief or rapid sounds.

Subsequently, a number of studies appeared that challenged this conceptualization of SLI and dyslexia. First, there have been frequent failures to replicate the finding of auditory temporal processing deficits in dyslexia and SLI (see McArthur \& Bishop, 2001, for a review). On its own, this is not particularly damaging to Tallal's (2000) theory. After all, her claim was not that all language and reading disability stems from auditory temporal processing deficits (see, e.g., Tallal \& Stark, 1982; Tallal, Townsend, Curtiss, \& Wulfeck, 1991) - it is to be expected that some children will have language or literacy problems that arise from other causes. Second, and more problematic for Tallal's position, is that her original finding (Tallal, 1980) of a strong correlation between nonword reading and auditory temporal processing has not generally been replicated (see, e.g., Bretherton \& Holmes, 2003). An exception is work by Witton and colleagues, who have found significant correlations between nonverbal auditory processing and nonword reading in three separate samples (Talcott et al., 2000; Witton et al., 1998, 2002). However, the largest effect was found for a task that involved discriminating a slow rate of frequency modulation $(2 \mathrm{~Hz})$ from an unmodulated tone, which thus measured sensitivity to sound changes across hundreds rather than tens of milliseconds. Furthermore, Bishop, Carlyon, Deeks, and Bishop (1999) found no deficit in detection of 2-Hz frequency modulation in children with SLI, and no association with nonword reading.

In the context of SLI, Bishop, Carlyon, et al. (1999) concluded that an auditory temporal deficit was neither necessary nor sufficient to account for language impairment. Similar arguments have been advanced by Ramus (2003) and S. Rosen (2003) in the case of dyslexia. Both authors concluded that (a) only a minority of children with dyslexia have auditory perceptual deficits, (b) the deficits that are seen are not restricted to brief or rapid stimuli, and (c) perceptual difficulties are frequently uncorrelated with phonological problems. Bailey and Snowling (2002) concurred, arguing that there is no evidence that nonverbal auditory deficits can adequately account for language and literacy problems in children.

Nevertheless, abnormalities of auditory perception are rather more common in children with language and literacy problems than in control groups, and this needs explaining. One possibility is that the deficits are co-occurring symptoms that have common etiological origins but are not causally linked to the language or literacy problems (Marshall, Snowling, \& Bailey, 2001). Another possibility suggested by Bishop, Carlyon, et al. (1999) is that having a perceptual deficit increases the likelihood that an underlying genetic risk for disorder will be manifest. This idea could explain why children who have perceptual deficits tend to be more impaired on language or literacy tasks than those who do not, while also accommodating the facts that many children with perceptual deficits do not have language or literacy problems (see also Briscoe et al., 2001) and many children with language or literacy problems do not have perceptual deficits.

It is important to be aware that the pattern of association between auditory deficits and phonological problems may change with age. One may be tempted to dismiss auditory deficit explanations as the distal cause of phonological deficit if there is no association between auditory measures and performance on phonological tasks. However, it is possible that some children have an auditory processing deficit early in life that subsequently resolves. This might affect how phonological representations are set up and leave a lasting legacy of phonological impairment. This is difficult to disprove unless we have longitudinal data from an early age, but is given some credence by studies that find evidence of associations between auditory discrimination problems in infancy and subsequent language development (Benasich, Thomas, Choudhury, \& Leppänen, 2002; Trehub \& Henderson, 1996).

In summary, deficits on phonological tasks appear to be far more reliable and striking than auditory deficits in both SLI and dyslexia. It is possible that auditory deficits are the distal cause of phonological problems in both clinical groups, but the auditory deficits are transient and thus not detected in older children. Another possibility is that auditory deficits are implicated in causing phonological problems in only a subset of children or that they are incidental associated deficits and not causally linked to the phonological impairments. A final possibility is that auditory impairment will exacerbate any phonological impairment that is present but is not the primary cause of such problems. However, claims that an auditory temporal processing hypothesis can provide a unified and general account of dyslexia and SLI appear premature.

Phonological memory. The genetic studies reviewed above drew attention to another phonological skill that is often deficient in heritable forms of language and literacy problems, namely nonword repetition - the ability to repeat unfamiliar polysyllabic sequences, such as dopelate or blonterstaping. This task is usually regarded as indexing a specialized short-term memory system designed for retaining phonological information over brief intervals (Gathercole \& Baddeley, 1990). Nonword repetition deficits have been demonstrated in several studies of both SLI (Bishop, North, \& Donlan, 1996; Briscoe et al., 2001; Botting \& ContiRamsden, 2001; Dollaghan \& Campbell, 1998; Edwards \& Lahey, 1998; Gathercole \& Baddeley, 1990; Gillam \& Van Kleek, 1996; Kamhi \& Catts, 1986; Stothard et al., 1998) and dyslexia (Brady, Poggie, \& Rapala, 1989; Brady, Shankweiler, \& Mann, 1983; Hulme \& Snowling, 1992; Kamhi \& Catts, 1986; Snowling, 1981; Snowling, Goulandris, Bowlby, \& Howell, 1986; Taylor, Lean, \& Schwartz, 1989; Van der Bon \& Van der Pijl, 1997; Van Daal \& Van der Leij, 1999). Like phonological awareness, nonword repetition appears to be influenced by literacy skill, insofar as illiterate adults do more poorly than literate controls (Castro-Caldas, Petersson, Reis, Stone-Elander, \& Ingvar, 1998). Nevertheless, preliterate children achieve fair levels of accuracy at nonword repetition, and ability on this task predicts subsequent literacy levels (Gathercole \& Baddeley, 1993). Furthermore, nonword repetition remains deficient in older children and adults whose early language impairment has resolved, suggesting it taps a core deficit that persists even when its behavioral consequences have been compensated for (Bishop et al., 1996).

Memory has not been discussed explicitly in the context of the triangle model, but it seems reasonable to suppose that the durability of activation plays a role when forming mappings between phonology and orthography, initially affecting the acquisition of letter-sound correspondences and, subsequently, letter sequences. 
If phonological representations are prone to rapid decay, one might also expect to see some impairment also in mapping between phonology and semantics, that is, acquisition of new vocabulary (Carroll \& Snowling, 2004).

In sum, although most of the emphasis in studies of dyslexia has been on phonological awareness, we suggest that phonological memory may be a more fruitful skill to investigate when studying the phonological origins of literacy problems in dyslexia and SLI. Deficits in this skill are commonly seen in both disorders, and although one cannot rule out an influence of reading ability on a task such as nonword repetition, it seems less prone than phonological awareness tasks to be influenced by orthographic knowledge.

\section{Deficits in Semantic Representations}

It is easy to see how weak phonological processing could affect the ability to map between phonology and orthography, but a phonological account has more difficulty in explaining poor reading comprehension. Indeed, many children who have phonological dyslexia do not have undue problems with comprehending text, provided they can decode the words. This is a point of contrast with SLI, for which there is evidence that some children struggle to understand text, even when they have read it accurately (Bishop \& Adams, 1990).

To understand the processes involved in reading comprehension, it can be useful to consider children whose literacy profile is the mirror image of dyslexia, in that they can read accurately, but with poor understanding of what is read. These so-called poor comprehenders seldom attract clinical concern and are typically identified by screening children from mainstream classes on a reading test that gives measures of both accuracy and comprehension, such as the Neale Analysis of Reading Ability (Neale, 1997). They have been described extensively by Oakhill (1993; Yuill \& Oakhill, 1991). Shankweiler et al. (1999) found this reading profile in $4.7 \%$ of a population of children referred for "learning problems" whose IQ was more than 80. However, Nation and Snowling (1997) and Stothard and Hulme (1995) have observed it in up to $10 \%$ of primary school children in unselected samples.

The language profile of poor comprehenders is strikingly different from that of children with dyslexia. Children with dyslexia and poor comprehenders both display verbal working memory deficits and naming difficulties, but the nature of the problem is different in the two disorders. Children with dyslexia have poor verbal short-term memory span, whereas poor comprehenders perform well on such simple memory tasks, yet their memory span for abstract words is poor (Nation, Adams, Bowyer-Crane, \& Snowling, 1999). Similarly, both groups of children find it difficult to name objects with low-frequency names, but whereas children with dyslexia make phonological naming errors, poor comprehenders are more likely to make visually based errors or no response (Nation, Marshall, \& Snowling, 2001). In short, the phonological skills of poor comprehenders are normal (Cain, Oakhill, \& Bryant, 2000; Nation \& Snowling, 1998b) but they show deficits in a wide range of language skills outside the phonological domain such as weak vocabulary and limitations of semantic knowledge (Nation \& Snowling, 1998b; Nation \& Snowling, 1999).
The triangle model predicts that children who have weak semantic skills should have difficulty when required to use the semantic pathway for reading. This prediction is supported by a study by Nation and Snowling (1998b), which showed that compared with reading-age-matched controls, poor comprehenders made more errors and were slower when reading words of low frequency, but did not differ in reading of high-frequency words. Moreover, there was a trend for the poor comprehenders to read exception words less well than controls. The single-word reading skills of poor comprehenders therefore resembled those of people with surface dyslexia, though it would be misleading to describe them as such because their word reading skills were age-appropriate.

Nation, Clarke, and Snowling (2002) considered whether poor comprehenders should be thought of as having SLI. They showed that the widespread language-processing difficulties of poor comprehenders were not simply a facet of low IQ; nonverbal abilities were well within the normal range, numerical skills were welldeveloped, and they had normal speed of processing. In a subsequent study, Nation, Clarke, Marshall, and Durand (2004) showed that a substantial number of poor comprehenders fulfill diagnostic criteria for SLI based on language tasks (between 17\% and 35\% depending on the criteria used). Clearly then, there are similarities between this population of children and those with SLI, but the finding that they have proficient phonological skills suggests they may be etiologically distinct from those with the more classic form of the disorder.

There is, therefore, something of a paradox. Poor comprehenders resemble children with SLI, but so too do those with classic developmental dyslexia, who display the opposite profile of reading impairment. Our resolution of the paradox, illustrated in Figure 1 , is to see semantic and phonological deficits as separable dimensions of literacy-related skill, both of which are impaired in SLI.

\section{Cognitive Processes: Beyond the Triangle Model}

The triangle model is restricted to single-word reading. However, children with SLI have oral language deficits that affect processing at the level of the sentence or the paragraph.

\section{Syntax}

Models such as the dual route and the triangle model (see Figure 5) were devised to account for single-word reading and therefore have had little to say about possible syntactic influences on literacy development. Even at the level of single words, knowledge of grammatical morphology influences spelling ability (Kemp \& Bryant, 2003; Nunes, Bryant, \& Bindman, 1997; Treiman \& Cassar, 1996). The importance of syntax for literacy becomes more apparent at the level of written sentences or paragraphs. The child who is unable to understand complex oral language is likely to have poor reading comprehension, given that many written texts make heavy use of complex clausal structures (Gough \& Tunmer, 1986; Perera, 1984).

Adams (1990) noted a further way in which syntax affects literacy development: by providing a sentence context in which words are interpreted and hence facilitating the meaning of words that are probable in that context (see Figure 6). Context is partic- 


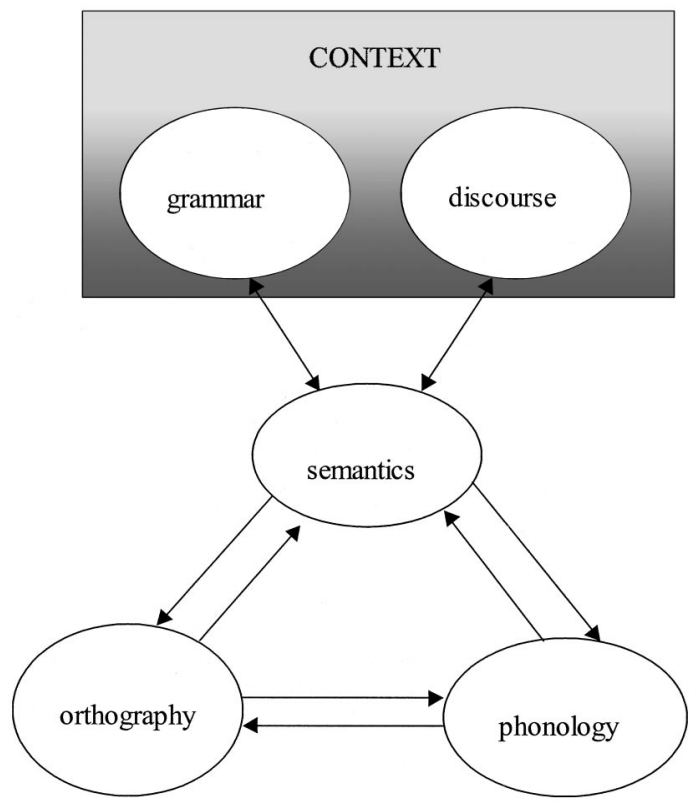

Figure 6. The triangle model extended. Adapted from "A Distributed, Developmental Model of Word Recognition and Naming," by M. S. Seidenberg and J. L. McClelland, 1989, Psychological Review, 96, p. 526. Copyright 1989 by the American Psychological Association.

ularly important when reading unfamiliar irregular words that cannot be decoded using letter-sound correspondences. It follows that children with weak mastery of syntax will be disadvantaged in literacy acquisition in several respects: They will have fewer contextual cues to help interpret novel words (Rego \& Bryant, 1993; Tunmer \& Chapman, 1998) and poorer understanding of the sentences they do succeed in decoding.

Syntactic deficits are a hallmark of SLI. It is beyond the scope of this article to review the theoretical accounts of this impairment (see L. B. Leonard, 1998), but there is a strong body of evidence that English-speaking children with SLI have disproportionate difficulty with certain grammatical morphemes, even when compared with younger normally developing children matched on mean length of utterance. They tend to omit tense markers, such as past tense -ed or third person singular $-\mathrm{s}$; to make case errors on pronouns (e.g., "him go there" instead of "he goes there"); and to omit the verb to be when functioning as auxiliary or copula (e.g., "He running" rather than "he is running"; "John big" rather than "John is big"). The difficulties with morphology can be seen in spontaneous speech samples (Rice \& Oetting, 1993), in sentence elicitation tasks (e.g., Rice, 2000; Norbury, Bishop, \& Briscoe, 2001; Van der Lely \& Ullman, 2001), and in tasks in which the child is required to judge the grammaticality of spoken sentences (Montgomery \& Leonard, 1998; Rice, Wexler, \& Redmond, 1999). Furthermore, children with SLI often produce only simple syntactic structures and have problems comprehending complex sentences (e.g., Bishop, 1982; Tallal, 1975; Van der Lely, 1996; Van der Lely \& Stollwerck, 1997). It seems likely, therefore, that syntactic as well as semantic deficits are implicated in poor reading in SLI.

Could syntactic problems also play a role in causing reading problems in dyslexia? The current conceptualization of dyslexia as a language-learning disorder is ambivalent on this point. Many researchers see the language disorder aspect of dyslexia as specifically having to do with phonological processing. For example, B. A. Shaywitz et al. (2002) stated, "There is now a strong consensus that the central difficulty in dyslexia reflects a deficit within the language system and, more particularly, in a lower level component, phonology [italics added]" (p. 101). Where semantic or syntactic deficits are found in children with reading disability, they are commonly regarded as secondary consequences of phonological impairment (Shankweiler \& Crain, 1986). The question is whether, by focusing on phonological impairments in poor readers, researchers may have neglected other linguistic deficits that might have an independent causal relationship to low literacy.

The problem for anyone aiming to establish the frequency of syntactic deficits in dyslexia is that the answer will be heavily influenced by the way in which dyslexia is defined. As illustrated in Figure 3, verbal abilities and literacy are moderately correlated in the general population. If one seeks out children who are poor readers despite good verbal IQ, it is far less likely that they will have poor syntactic skills than if children are recruited on the basis of reading deficits and normal nonverbal ability. Several studies that report syntactic deficits in dyslexia adopted the latter strategy and did not match the dyslexics on IQ with a control group (e.g., Byrne, 1981; Joanisse, Manis, Keating, \& Seidenberg, 2000).

Overall, syntactic deficits are likely to be a source of difference rather than similarity between SLI and dyslexia, provided the latter disorder is defined according to relatively strict discrepancy criteria. Taken together with the more marked vocabulary impairments in SLI, this accounts for the finding that problems of reading comprehension are common in SLI (Bishop \& Adams, 1990) but less so in classic dyslexia (Frith \& Snowling, 1983).

\section{Discourse Skills}

Written texts require the child not only to read individual words but also to understand sentences and tie these together into a coherent whole. This process requires the child to make inferences (Winne, Graham, \& Prock, 1993). There is not scope in this review to discuss discourse influences on literacy development in any detail, but we simply flag up that contextual influences on interpretation of texts go beyond the sentence level to encompass interpretive processes that tie sentences together into a meaningful discourse. We can anticipate that children with SLI, who often have difficulties with literal and inferential comprehension of oral narratives (Bishop \& Adams, 1992), are likely to have even greater problems when they have to simultaneously apply their developing decoding skills and attempt to comprehend multisentence texts. Again, in this respect, we see SLI as contrasting with dyslexia, where ability to use context to decode texts is often an area of strength.

\section{Toward a Model of the Cognitive Relationships Between Developmental Dyslexia and SLI}

We have reviewed evidence that a child can encounter reading difficulties because of problems with phonological or semantic language processes or because of poor memory resources, all of which can affect the mappings between orthography and phonology and the development of orthographic representations. 
Moreover, we have underlined a double dissociation between phonological dyslexia (that primarily affects mapping between orthography and phonology) and specific deficits in reading comprehension (primarily affecting mapping between orthography and semantics). However, pure dissociations are rare in development; for instance, poor readers often have problems reading both exception words and nonwords, a minority have specific deficits in exception word reading (surface dyslexia) and some also have problems with reading comprehension (backward readers). Moreover, it is possible that some experience visual difficulties that impair orthographic representations (Seidenberg, 1992; Stein \& Talcott, 1999). A clearer understanding of individual differences in dyslexia is a prerequisite for interpreting its relationship with SLI.

The most comprehensive attempt to date to understand individual variation in developmental dyslexia within the connectionist framework was reported by Harm and Seidenberg (1999). Their formulation was cast with reference to a model containing a phonological attractor network that was first pretrained to allow it to encode information about the phonological structure of English. Subsequently, it was trained on mappings between orthography and phonology. An important function of this attractor network was to complete or repair incomplete or noisy phonological inputs using knowledge represented by weights on connections between input and output units. To simulate phonological dyslexia, the network's capacity to represent phonological information was reduced. Harm and Seidenberg's simulations showed that the more severe the impairment that they imposed on the phonological network, the greater the nonword reading deficit. In the case of the most severe impairments, exception word reading was also affected. In contrast, altering the learning parameter to a nonoptimal level affected the model's capacity to read exception words, with a lesser effect on nonword reading.

Harm and Seidenberg's (1999) simulations suggested that the severity of a child's phonological deficit will affect their reading profile at the single-word level. Griffiths and Snowling (2002) presented behavioral evidence that was consistent with this view: In a group of children with dyslexia both phonological awareness and phonological memory were unique predictors of nonword reading when word reading skill was controlled. In contrast, an environmental measure of the child's familiarity with books was a predictor of individual differences in exception word reading.

\section{Learning to Read: The Role of Nonphonological Language Skills}

We have emphasized that in addition to the role of phonology in learning to read, there are also other sources of individual variation, notably a child's semantic skills and ability to use linguistic context (Nation \& Snowling, 1998a), as illustrated in the extended version of the Seidenberg and McClelland (1989) model in Figure 6 . To the extent that language skills beyond phonology facilitate decoding, children with SLI will be at a disadvantage in learning to read because they will be less sensitive to the contexts that feed the semantic pathway. In addition, reading comprehension skills that depend on the integration of concepts activated by the text (Kintsch, 1998) will also be affected. A further important influence on the outcome of the child's literacy development involves interactions within the developing reading system itself.
Plaut et al. (1996) conceptualized the interactive nature of reading as a division of labor between the phonological pathway and the semantic pathway. The basic idea was that children start out by devoting their resources to setting up mappings between orthography and phonology in the phonological pathway. Although it would be simplistic to think that the semantic attributes of words are of no consequence at this early stage, it is nonetheless the case that phonological skills are unique predictors of reading and spelling in the first few school years. In contrast, a case can be made for the increasingly important role of semantic and syntactic skills as development proceeds (cf. Leach, Scarborough, \& Rescorla, 2003; Whitehurst \& Fischel, 2000).

The division of labor hypothesis offers a way of considering how children with dyslexia learn to read in the face of phonological difficulties. Those children who have good language comprehension can use top-down semantic and syntactic skills to bootstrap ineffective decoding skills (Hulme \& Snowling, 1992; Snowling et al., 2003). Nation and Snowling (1998a) tested this idea by comparing the ability of dyslexic readers and normal decoders, matched on reading age, to read a set of words with inconsistent spellings that could not be pronounced correctly using only the phonological pathway. The children were presented with target words either in isolation or following a spoken sentence context that placed a constraint on the final word to be read. The reading accuracy of children with dyslexia was better than that of younger controls when words were presented in context but not when they were presented in isolation. The findings of this experiment suggest that dyslexic readers may be able to compensate for decoding deficits to some extent by relying on contextual cues to support decoding processes. In terms of the triangle model, semantic activation from the sentence frame primes the semantic pathway and facilitates the pronunciation of unfamiliar words. This compensatory resource would not be available to children with SLI. It can be predicted therefore that, given equivalent levels of phonological deficit, children with SLI should learn to read more slowly than children with classic dyslexia; indeed, their reading difficulties might be expected to become relatively more marked with age.

Contrary to this hypothesis, Goulandris, Snowling, and Walker (2000) reported that when compared with children who had a childhood diagnosis of dyslexia, children with a preschool history of SLI whose oral language difficulties had resolved had relatively less severe literacy problems. Naucler and Magnusson (2002) obtained similar findings in a Swedish sample. To account for such counterintuitive results, it is important to note that a division of labor toward the semantic pathway (as posited for dyslexia), although facilitating reading, could have a deleterious effect on a child's capacity to learn orthographic sequences. The reason for this is that orthographic learning in an alphabetic system in which spelling units connect to phonemes depends on setting up finegrained connections between orthography and phonology. It is arguable that it is only when words are processed via the phonological pathway that orthography-phonology mappings (be they consistent or inconsistent) are activated (Harm et al., 2003). If the child is not using this phonological pathway but rather is relying on context, connections will be formed at a coarser level between semantics and whole-word- or morpheme-based phonology. Such learning is not sufficient to subserve English spelling or to read novel words that require segmentation. Indeed, observations of 
people with dyslexia suggest that, although reading can be compensated, spelling deficits are more enduring. Furthermore, just as the use of compensatory reading strategies has a deleterious impact on spelling development, in cases in which the semantic pathway is used less (such as in SLI) there could be relative benefits for spelling performance. In a similar vein, the spelling of children with hearing impairments is often better developed than their reading skills predict (Burden \& Campbell, 1994), perhaps because their attention is directed more to the visual aspects of printed words than is the case among children with more proficient language and phonology.

In summary, reading development is a highly interactive process, and the orthographic system is shaped at least in part by how it is used; thus, the profile of reading difficulty exhibited by an individual child can be expected to change with age. In line with this view, Snowling et al. (2000) found that the nature of the reading difficulties of children with resolved and persistent SLI changed from primarily affecting reading comprehension at the age of 8 to also affecting reading accuracy at the age of 15 (see Leach et al., 2003, for further discussion of later emerging reading disabilities). Therefore, reading needs to be thought of as a dynamic system, and its development multicausal. Moreover, more severe basic language impairments do not necessarily map to more severe literacy problems because of the division of labor between resources shared by language and literacy. We propose that in dyslexia, the imbalance between phonological and semantic skills creates a different profile of reading and spelling impairment to that observed in SLI, where phonological and semantic skills show more equivalent degrees of impairment. Thus, although the cognitive deficits that carry the risk of reading difficulty may be similar in dyslexia and in SLI, this does not mean they are the same disorder.

\section{Conclusion}

\section{Language and Literacy Skills in SLI and Dyslexia}

SLI and developmental dyslexia present tantalizing similarities. Young children with a family history of dyslexia have delays in early oral language development, suggesting phenotypic and etiological overlap with SLI. And in older children with developmental dyslexia, it is often possible to demonstrate impairments on oral language tasks that do not involve any reading or writing. Furthermore, at the cognitive level, children with SLI usually have the same core phonologic impairments that have come to be regarded as characteristic of developmental dyslexia. It is easy to see why there has been a growing trend to collapse these diagnostic categories, or at least treat them as points on a continuum of severity rather than distinct disorders.

One point, however, to emerge from this review is that a unidimensional model of reading disability is inadequate to capture the relationship between dyslexia and SLI. Several sources of evidence converge on the view that nonphonological aspects of language play an important role in literacy development. These include studies of preschool predictors of literacy development, both in typically developing children and in those with speech and language problems, and studies of poor comprehenders. The notion that semantic and syntactic skills play a role in the development of literacy is not a new one: Similar ideas were expressed as long ago as 1986 by Gough and Tunmer. However, in practice, the emphasis of much research on dyslexia, and many intervention approaches, has been on phonological processes.

Even when strong associations are found between nonphonological language skills and later literacy outcome, these are often simply "corrected for" in a statistical analysis and treated more like nuisance variables than important causal factors. In contrast, the triangle model of reading development emphasizes the interplay between semantic, phonological, and orthographic skills, and thus restores semantics to a central position. Viewed from this perspective, we have reconceptualized the relationship between SLI and dyslexia in terms of a two-dimensional space, as illustrated in Figure 1. Note that this conceptualization treats classic SLI as a case of double deficit, in which both phonological and nonphonological language processes are impaired, thus impeding development of mappings to orthography via either route. In this model, we place poor comprehenders in a different quadrant of the diagram from classic SLI, because all the evidence indicates that these are children who have weak semantic processing and normal phonological skills. Nation et al. (2004) noted that many poor comprehenders would meet a traditional psychometric definition of SLI in that they have low scores on oral language tests coupled with normal nonverbal ability. Nevertheless, they are typically children who have never been referred for language assessment. This suggests that weak semantic skills and poor comprehension alone may not be sufficient to attract the concern of parents and professionals, and that it is only when structural aspects of oral language (i.e., phonology and/or syntax) are also affected that the difficulties become obvious.

If this is correct, it has implications for how SLI is diagnosed. For instance, in the epidemiological study by Tomblin et al. (1997), only $29 \%$ of the children who met psychometric criteria for SLI had previously been identified by clinical services. We suspect that many of the unrecognized cases of SLI in this sample may resemble poor comprehenders. As is evident from Figure 1, if we include children such as these as cases of SLI, then we will dilute any overlap with classic dyslexia.

Although we have labeled the quadrants of Figure 1 with categorical terms, we regard the two underlying dimensions as continuous, and we suspect there may well be children whose profile of deficit is midway between the categories we have listed. We also stress that this diagram has been devised to capture the most salient factors relevant to the dyslexia-SLI distinction. One should not conclude from this that these are the only factors that affect literacy acquisition. Other variables, such as visual perception, speed of processing, and attention may play a role in literacy development for some children.

One advantage of the quadrant model shown in Figure 1 is that it appears to relate coherently to both neurobiological and genetic findings. Thus it sits nicely with the functional imaging data that suggest similar phonological processing problems exist in both SLI and dyslexia, but it also can accommodate the findings of C. M. Leonard et al. $(2001,2002)$ showing that poor readers with comprehension difficulties had a different pattern of structural brain characteristics from those with specific phonological deficits. From the perspective of genetics, evidence from a range of studies supports the view that deficits on the phonological dimension are heritable and that these share genetic variance with phonological decoding skills, whereas there is much less evidence for genetic 
influence on literacy deficits that are not associated with specific phonological difficulties (e.g., Bishop, 2001; Bishop et al., 2004; Castles et al., 1999).

The quadrant model provides a useful framework for thinking about subtypes of reading impairment and their relation to language difficulties, but it is nevertheless an oversimplification. One goal for future research will be to unpack the concepts of phonological and nonphonological language impairment to investigate the component skills contributing to these dimensions. For example, when considering what is meant by phonological deficit researchers can distinguish between underspecified phonological representations, difficulty in segmentation, rapid decay of representations, and problems in learning and automatizing mappings between phonology and orthography. In addition, it is important to stress the reciprocal nature of the relationship between phonological and orthographic representations, which includes an influence of literacy skill on the nature of phonological representations, as well as the converse. The nonphonological language dimension subsumes a wide range of underlying skills that may make distinctive contributions to literacy development. Most of the readingrelated research in this area has focused on semantics, but we have argued that syntactic and discourse skills also impinge on learning to read and write and on reading comprehension. Where syntactic difficulties have been found in association with literacy deficits, there has been a tendency to regard them as secondary consequences of phonological difficulties. We suggest that if one focuses on ability to understand texts, rather than single-word reading, a distinct role of syntactic skills becomes more evident.

\section{Subtypes of Reading Disorder}

The traditional distinction between phonological and surface dyslexia does not map neatly onto the quadrant model shown in Figure 1. The hallmarks of surface dyslexia are poor exception word reading in the face of normal nonword reading and, in this respect, map most naturally to Quadrant D, where poor comprehenders, who make similar kinds of errors, are located. However, bear in mind that the surface dyslexia profile is the behavioral manifestation of a word-level reading difficulty, whereas poor comprehension is not. Surface dyslexia is a pattern of behavior that is observed when reading single words with no time pressure.

It is clear from clinical experience that some children with dyslexia can read nonwords accurately given unlimited time and read exception words as though they were regular words (making the regularization errors; e.g., reading come as comb). However, when people are required to read under time pressure, the tendency to make regularization errors declines (Hendriks \& Kolk, 1997). The profile of surface dyslexia may not therefore be robust; indeed, Manis and Bailey (2001) reported that it is less stable across age than is phonological dyslexia. Furthermore, surface dyslexia in children has been associated variously with the overuse of taught phonic strategies, limited print exposure, and slow speed of processing (Griffiths, 1999). Moreover, children who show the profile are not free of phonological difficulties, although these are milder than in phonological dyslexia (Manis et al., 1996; Snowling et al., 1998). A parsimonious explanation is that the surface profile is seen in children with mild phonological impairments whose slow speed of processing compromises the ability to establish orthographic representations and who by default use the phono- logical pathway laboriously when reading. It would not be surprising if such children developed an aversion to reading because of a lack of fluency; thus, they limit their own exposure to books. Within this view, surface and phonological dyslexia are on a continuum of severity (Griffiths \& Snowling, 2002) within Quadrant $\mathrm{A}$, bearing in mind that cognitive and experiential factors may modify their behavioral expression.

The other group of children who warrant discussion within this framework are backward readers. According to Stanovich and Siegel (1994) these children share the phonological deficits of dyslexia but have additional cognitive problems, including poor working memory and difficulties with oral cloze and sentence construction tasks, suggesting they fall on a continuum of language disorders. Swan and Goswami (1997a) reported that backward readers performed at the same level as children with dyslexia on phonological awareness tasks and had similar problems with word retrieval mechanisms for naming. However, their naming problems were associated with vocabulary deficits, whereas those of the children with dyslexia were not (Swan \& Goswami, 1997b). It is plausible therefore that these children resemble children with SLI, although their nonverbal IQs would normally be lower. Because, to our knowledge, no study has assessed the language skills of backward readers comprehensively, it is difficult to ascertain the severity of their nonphonological language problems. We would for the present, place them midway between dyslexia and SLI on the left side of Figure 1.

\section{Implications for Diagnosis, Assessment, and Intervention}

The conventional psychometric discrepancy definition of dyslexia will not identify in which quadrant of the model a child falls. If we were to treat as dyslexic any children with poor reading accuracy or comprehension in the context of normal performance (nonverbal) IQ, then we would be likely to select children with a mixture of poor comprehension, classic SLI, and classic dyslexia. If we identify children who have poor reading accuracy in relation to verbal IQ, we are likely to capture a higher proportion of cases of children with classic dyslexia who have relatively pure phonological difficulties. If we adopt the procedure advocated by Frith (1997) and others, and equate dyslexia with poor phonological processing, our sample will include cases of both classic SLI and classic dyslexia, as well as backward readers. Overall, the procedure we adopt should depend on the purpose of the diagnostic exercise. However, we argue that in both research and clinical contexts it will usually be helpful to distinguish between Quadrants $\mathrm{A}, \mathrm{C}$, and D. For instance, children with severe and selective reading impairments in the context of otherwise normal oral language skills are likely to have a different neurobiological and genetic profile, and also a different outcome, from those who have more global impairments affecting all aspects of oral as well as written language (see also Morris et al., 1998).

If we accept that the quadrant model is a useful way of categorizing children, then the most obvious approach to assessment would be to use measures that directly tap the two key dimensions of phonological and nonphonological skills. To circumvent the possible reciprocal influence of (poor) reading on phoneme awareness, the assessment of phonological skills should go beyond metalinguistic tasks and include tests of phonological memory, such as nonword repetition. In the assessment of nonphonological 
language skills, tests of vocabulary development and grammatical sensitivity would be useful (for illustrative examples, see Lum et al., 2000). The procedure recommended by Stanovich (1994) of comparing listening comprehension with reading comprehension will also aid the differential diagnosis of classic dyslexia, in which listening comprehension is normal, and SLI, in which understanding is poor for both aural and written materials (Bishop \& Adams, 1990).

Finally, we turn to the issue of intervention. There is now a large body of evidence suggesting that, while training in phonological awareness brings modest benefits for poor readers (Ehri et al., 2001), such training brings substantial benefits if it is combined with training in letter knowledge and word reading and the linkages between phonological and orthographic units is made explicit (Harm et al., 2003; Hatcher, Hulme, \& Ellis, 1994; Hatcher, Hulme, \& Snowling, 2004). Moreover, such programs are effective for the development of word-level decoding skills of backward readers as well as those with discrepancy-defined disorders (Hatcher, 2000). Nonetheless, it is becoming increasingly clear that not all readers respond well to such programs of intervention (Torgesen, 2000). There is also evidence that phonologically based intervention programs can have rather specific effects, improving phonological reading skills but failing to result in fluent word recognition (Olson, Wise, Johnson, \& Ring, 1997; Wise, Ring, \& Olson, 1999). Taken together, these findings raise the issue of whether some poor readers, whose phonological difficulties are either severe or complex (co-occurring with nonphonological deficits), require a different form of intervention (Shatil \& Share, 2003). Hatcher and Hulme (1999) showed that initial phonological awareness was the best predictor of progress in their reading with phonology intervention program (Hatcher et al., 1994), but verbal IQ was an additional predictor of progress in reading comprehension. Programs that neglect verbal skills beyond phonology run the risk of leaving untreated fundamental skills that are important for both decoding and reading comprehension. Programs of semantic intervention to support the development of word recognition would seem to be timely (Norbury \& Chiat, 2000), and these may go some way toward addressing the issue of "difficult-toremediate" poor readers (Vellutino et al., 1996).

\section{References}

Adams, M. J. (1990). Beginning to read: Thinking and learning about print. Cambridge, MA: MIT Press.

American Psychiatric Association. (1994). Diagnostic and statistical manual of mental disorders (4th ed.). Washington, DC: Author.

Aram, D. M., Ekelman, B. L., \& Nation, J. E. (1984). Preschoolers with language disorders: 10 years later. Journal of Speech and Hearing Research, 27, 232-244.

Aram, D. M., \& Nation, J. E. (1980). Preschool language disorders and subsequent language and academic difficulties. Journal of Communication Disorders, 13, 159-170.

Bailey, P. J., \& Snowling, M. J. (2002). Auditory processing and the development of language and literacy. British Medical Bulletin, 63, 135-146.

Bartlett, C. W., Flax, J. F., Logue, M. W., Vieland, V. J., Bassett, A. S., Tallal, P., \& Brzustowicz, L. M. (2002). A major susceptibility locus for specific language impairment is located on 13q21. American Journal of Human Genetics, 71, 45-55.

Benasich, A. A., Thomas, J. J., Choudhury, N., \& Leppänen, P. H. T. (2002). The importance of rapid auditory processing abilities to early language development: Evidence from converging methodologies. Developmental Psychobiology, 40, 278-292.

Bird, J., Bishop, D. V. M., \& Freeman, N. H. (1995). Phonological awareness and literacy development in children with expressive phonological impairments. Journal of Speech and Hearing Research, 38, $446-462$.

Bishop, D. V. M. (1982). Comprehension of spoken, written, and signed sentences in childhood language disorders. Journal of Child Psychology and Psychiatry, 23, 1-20.

Bishop, D. V. M. (1994). Is specific language impairment a valid diagnostic category? Genetic and psycholinguistic evidence. Philosophical Transactions of the Royal Society, Series B, 346, 105-111.

Bishop, D. V. M. (1997). Uncommon understanding. Hove, England: Psychology Press.

Bishop, D. V. M. (2001). Genetic influences on language impairment and literacy problems in children: Same or different? Journal of Child Psychology and Psychiatry, 42, 189-198.

Bishop, D. V. M. (2002a). Cerebellar abnormalities in developmental dyslexia: Cause, correlate or consequence? Cortex, 38, 491-498.

Bishop, D. V. M. (2002b). The role of genes in the etiology of specific language impairment. Journal of Communication Disorders, 35, 311328.

Bishop, D. V. M. (2002c). Speech and language difficulties. In M. Rutter \& E. Taylor (Eds.), Child and adolescent psychiatry: Modern approaches (pp. 664-681). Oxford, England: Blackwell.

Bishop, D. V. M., \& Adams, C. (1990). A prospective study of the relationship between specific language impairment, phonological disorders and reading retardation. Journal of Child Psychology and Psychiatry, 31, 1027-1050.

Bishop, D. V. M., \& Adams, C. (1992). Comprehension problems in children with specific language impairment: Literal and inferential meaning. Journal of Speech and Hearing Research, 35, 119-129.

Bishop, D. V. M., Adams, C. V., \& Norbury, C. F. (2004). Using nonword repetition to distinguish genetic and environmental influences on early literacy development: A study of 6-year-old twins. American Journal of Medical Genetics: Part B. Neuropsychiatric Genetics, 129, 94-96.

Bishop, D. V. M., Bishop, S. J., Bright, P., James, C., Delaney, T., \& Tallal, P. (1999). Different origin of auditory and phonological processing problems in children with language impairment: Evidence from a twin study. Journal of Speech, Language, and Hearing Research, 42, $155-168$.

Bishop, D. V. M., \& Butterworth, G. E. (1980). Verbal-performance discrepancies: Relationship to birth risk and specific reading retardation. Cortex, 16, 375-390.

Bishop, D. V. M., Carlyon, R. P., Deeks, J. M., \& Bishop, S. J. (1999). Auditory temporal processing impairment: Neither necessary nor sufficient for causing language impairment in children. Journal of Speech, Language, and Hearing Research, 42, 1295-1310.

Bishop, D. V. M., \& Clarkson, B. (2003). Written language as a window into residual language deficits: A study of children with persistent and residual speech and language impairments. Cortex, 39, 215-237.

Bishop, D. V. M., North, T., \& Donlan, C. (1996). Nonword repetition as a behavioral marker for inherited language impairment: Evidence from a twin study. Journal of Child Psychology and Psychiatry, 37, 391-403.

Boder, E. (1973). Developmental dyslexia: A diagnostic approach based on three atypical reading-spelling patterns. Developmental Medicine and Child Neurology, 15, 663-687.

Botting, N., \& Conti-Ramsden, G. (2001). Non-word repetition and language development in children with specific language impairment (SLI). International Journal of Language and Communication Disorders, 36, 421-432.

Bradley, L., \& Bryant, P. E. (1983, February 3). Categorising sounds and learning to read-A causal connection. Nature, 301, 419-521.

Brady, S., Poggie, E., \& Rapala, M. M. (1989). Speech repetition abilities 
in children who differ in reading skill. Language and Speech, 32, $109-122$.

Brady, S., Shankweiler, D., \& Mann, V. (1983). Speech perception and memory coding in relation to reading ability. Journal of Experimental Child Psychology, 35, 345-367.

Bretherton, L., \& Holmes, V. M. (2003). The relationship between auditory temporal processing, phonemic awareness, and reading disability. Journal of Experimental Child Psychology, 84, 218-243.

Briscoe, J., Bishop, D. V. M., \& Norbury, C. F. (2001). Phonological processing, language, and literacy: A comparison of children with mildto-moderate sensorineural hearing loss and those with specific language impairment. Journal of Child Psychology and Psychiatry, 42, 329-340.

Burden, V., \& Campbell, R. (1994). Development of word coding skills in the born deaf: An experimental study of deaf school leavers. British Journal of Developmental Psychology, 12, 331-349.

Byrne, B. (1981). Deficient syntactic control in poor readers: Is a weak phonetic memory code responsible? Applied Psycholinguistics, 2, 201212.

Byrne, B. (1998). The foundation of literacy: The child's acquisition of the alphabetic principle. Philadelphia: Psychology Press.

Byrne, B., Fielding-Barnsley, R., Ashley, L., \& Larsen, K. (1997). Assessing the child's contribution to reading acquisition: What we know and what we don't know. In B. Blachman (Ed.), Cognitive and linguistic foundations of reading acquisition (pp. 265-286). Hillsdale, NJ: Erlbaum.

Cain, K., Oakhill, J., \& Bryant, P. E. (2000). Phonological skills and comprehension failure: A test of the phonological processing deficit hypothesis. Reading and Writing, 13, 31-56.

Caparulo, B. K., Cohen, D. J., Rothmann, S. L., Young, J. G., Katz, J. D., Shaywitz, S. E., \& Shaywitz, B. A. (1981). Computed tomographic brain scanning in children with developmental neuropsychiatric disorders. Journal of the American Academy of Child Psychiatry, 20, 338-357.

Carroll, J. M., \& Snowling, M. J. (2004). Language and phonological skills in children at high-risk of reading difficulties. Journal of Child Psychology and Psychiatry, 45, 631-640.

Carroll, J. M., Snowling, M. J., Hulme, C., \& Stevenson, J. (2003). The development of phonological awareness in preschool children. Developmental Psychology, 39, 913-923.

Castles, A., \& Coltheart, M. (1993). Varieties of developmental dyslexia. Cognition, 47, 149-180.

Castles, A., \& Coltheart, M. (2004). Is there a causal link from phonological awareness to success in learning to read? Cognition, 91, 77-111.

Castles, A., Datta, H., Gayan, J., \& Olson, R. K. (1999). Varieties of developmental reading disorder: Genetic and environmental influences. Journal of Experimental Child Psychology, 72, 73-94.

Castro-Caldas, A., Petersson, K. M., Reis, A., Stone-Elander, S., \& Ingvar, M. (1998). The illiterate brain: Learning to read and write during childhood influences the functional organization of the adult brain. Brain, 121, 1053-1063.

Catts, H. W. (1991). Early identification of dyslexia: Evidence from a follow-up study of speech-language impaired children. Annals of Dyslexia, 41, 163-177.

Catts, H. W. (1993). The relationship between speech-language and reading disabilities. Journal of Speech and Hearing Research, 36, 948-958.

Catts, H. W., Fey, M. E., Tomblin, J. B., \& Zhang, X. (2002). A longitudinal investigation of reading outcomes in children with language impairments. Journal of Speech, Language, and Hearing Research, 45, $1142-1157$.

Catts, H. W., \& Kamhi, A. G. (1999). Language and learning disabilities. London: Allyn \& Bacon.

Clark, M. M., \& Plante, E. (1998). Morphology of the inferior frontal gyrus in developmentally language-disordered adults. Brain and Language, 61, 288-303.

Cohen, M., Campbell, R., \& Yaghmai, F. (1989). Neuropathological ab- normalities in developmental dysphasia. Annals of Neurology, 25, 567570.

Conti-Ramsden, G., Botting, N., Simkin, Z., \& Knox, E. (2001). Follow-up of children attending infant language units: Outcomes at 11 years of age. International Journal of Language and Communication Disorders, 36, 207-219.

Cossu, G., Shankweiler, D., Liberman, I., Katz, L., \& Tola, G. (1988). Awareness of phonological segments and reading ability in Italian children. Applied Psycholinguistics, 9, 1-16.

Dalby, M. (1977). Aetiological studies in language retarded children. Neuropaediatrie, 8(Suppl.), 499-500.

DeFries, J. C., \& Alarcón, M. (1996). Genetics of specific reading disability. Mental Retardation and Developmental Disabilities Research Reviews, 2, 39-47.

De Jong, P. F., \& Van der Leij, A. (1999). Specific contributions of phonological abilities to early reading acquisition: Results from a Dutch latent variable longitudinal study. Journal of Educational Psychology, 91, 450-476.

Denays, R., Tondeur, M., Foulon, M., Verstraeten, F., Ham, H., Piepsz, A., \& Noel, P. (1989). Regional brain blood flow in congenital dysphasia: Studies with technetium-99m HM-PAO SPECT. Journal of Nuclear Medicine, 30, 1825-1829.

Dodd, B. (1995). Differential diagnosis and treatment of children with speech disorder. London: Whurr.

Dollaghan, C., \& Campbell, T. F. (1998). Nonword repetition and child language impairment. Journal of Speech, Language, and Hearing Research, 41, 1136-1146.

Durgunoglu, A. Y., \& Oney, B. (1999). A cross-linguistic comparison of phonological awareness and word recognition. Reading and Writing: An Interdisciplinary Journal, 11, 281-299.

Eckert, M. A., Leonard, C. M., Richards, T. L., Aylward, E. H., Thomson, J., \& Berninger, V. W. (2003). Anatomical correlates of dyslexia: Frontal and cerebellar findings. Brain, 126, 482-494.

Edwards, J., \& Lahey, M. (1998). Nonword repetitions of children with specific language impairment: Exploration of some explanations for their inaccuracies. Applied Psycholinguistics, 19, 279-309.

Ehri, L. C., Nunes, S. R., Willows, D. M., Schuster, B., Yaghoub-Zadeh, Z., \& Shanahan, T. (2001). Phonemic awareness instruction helps children learn to read: Evidence from the National Reading Panel's metaanalysis. Reading Research Quarterly, 36, 250-287.

Elbro, C., Borstrom, I., \& Petersen, D. K. (1998). Predicting dyslexia from kindergarten: The importance of distinctness of phonological representations of lexical items. Reading Research Quarterly, 33, 36-60.

Fawcett, A. J., Nicolson, R. I., \& Maclagan, F. (2001). Cerebellar tests differentiate between groups of poor readers with and without IQ discrepancy. Journal of Learning Disabilities, 34, 119-135.

Felsenfeld, S., Broen, P. A., \& McGue, M. (1992). A 28-year follow-up of adults with a history of moderate phonological disorder: Linguistic and personality results. Journal of Speech and Hearing Research, 35, 11141125.

Fisher, S. E., \& DeFries, J. C. (2002). Developmental dyslexia: Genetic dissection of a complex cognitive trait. Nature Reviews, Neuroscience, 3, 767-780.

Flax, J. F., Realpe-Bonilla, T., Hirsch, L. S., Brustowicz, L. M., Bartlett, C. W., \& Tallal, P. (2003). Specific language impairment in families: Evidence for co-occurrence with reading problems. Journal of Speech, Language, and Hearing Research, 46, 530-543.

Frith, U. (1997). Brain, mind and behavior in dyslexia. In C. Hulme \& M. Snowling (Eds.), Dyslexia: Biology, cognition and intervention (pp. 1-19). London: Whurr.

Frith, U., \& Snowling, M. J. (1983). Reading for meaning and reading for sound in autistic and dyslexic children. British Journal of Developmental Psychology, 1, 329-342.

Galaburda, A. M., Sherman, G. F., Rosen, G. D., Aboitiz, F., \& Ge- 
schwind, N. (1985). Developmental dyslexia: Four consecutive cases with cortical anomalies. Annals of Neurology, 18, 222-233.

Gallagher, A., Frith, U., \& Snowling, M. (2000). Precursors of literacy delay among children at genetic risk of dyslexia. Journal of Child Psychology and Psychiatry, 41, 202-213.

Gathercole, S. E., \& Baddeley, A. D. (1990). Phonological memory deficits in language disordered children: Is there a causal connection? Journal of Memory and Language, 29, 336-360.

Gathercole, S. E., \& Baddeley, A. D. (1993). Phonological working memory: A critical building block for reading development and vocabulary acquisition? European Journal of Psychology of Education, 8, 259-272.

Gayan, J., \& Olson, R. K. (2001). Genetic and environmental influences on orthographic and phonological skills in children with reading disabilities. Developmental Neuropsychology, 20, 483-507.

Georgiewa, P., Rzanny, R., Gaser, C., Gerhard, U., Vieweg, U., Freesmeyer, D., et al. (2002). Phonological processing in dyslexic children: A study combining functional imaging and event-related potentials. Neuroscience Letters, 318, 5-8.

Gillam, R. B., \& Van Kleek, A. (1996). Phonological awareness training and short-term working memory: Clinical implications. Topics in Language Disorders, 17, 72-81.

Gough, P. B., \& Tunmer, W. E. (1986). Decoding, reading and reading disability. Remedial and Special Education, 7, 6-10.

Goulandris, N. (2003). Dyslexia in different languages: Cross-linguistic comparisons. London: Whurr.

Goulandris, N., Snowling, M. J., \& Walker, I. (2000). Is dyslexia a form of specific language impairment? A comparison of dyslexic and language impaired children as adolescents. Annals of Dyslexia, 50, 103-120.

Griffiths, Y. M. (1999). Individual differences in developmental dyslexia. York, England: University of York.

Griffiths, Y. M., \& Snowling, M. J. (2002). Predictors of exception word and nonword reading in dyslexic children: The severity hypothesis. Journal of Educational Psychology, 94, 34-43.

Grigorenko, E. L., Wood, F. B., Meyer, M. S., Hart, L. A., Speed, W. C., Shuster, A., \& Pauls, D. L. (1997). Susceptibility loci for distinct components of developmental dyslexia on chromosomes 6 and 15 . American Journal of Human Genetics, 60, 27-39.

Grigorenko, E. L., Wood, F. B., Meyer, M., \& Pauls, D. L. (2000). Chromosome $6 p$ influences on different dyslexia related cognitive processes: Further confirmation. American Journal of Human Genetics, 66, 715-723.

Hallgren, B. (1950). Specific dyslexia. Acta Neurologica and Psychiatrica Scandinavica Supplement, 65, 1-287 (whole issue).

Harm, M. W., McCandliss, B. D., \& Seidenberg, M. (2003). Modeling the successes and failures of interventions for disabled readers. Scientific Studies of Reading, 7, 155-183.

Harm, M. W., \& Seidenberg, M. S. (1999). Phonology, reading, and dyslexia: Insights from connectionist models. Psychological Review, 106, 491-528.

Hatcher, P. J. (2000). Sound links in reading and spelling with discrepancydefined dyslexics and children with moderate learning difficulties. Reading and Writing: An Interdisciplinary Journal, 13, 257-272.

Hatcher, P. J., \& Hulme, C. (1999). Phonemes, rhymes and intelligence as predictors of children's responsiveness to remedial reading instruction: Evidence from a longitudinal intervention study. Journal of Experimental Child Psychology, 72, 130-153.

Hatcher, P., Hulme, C., \& Ellis, A. W. (1994). Ameliorating early reading failure by integrating the teaching of reading and phonological skills: The phonological linkage hypothesis. Child Development, 65, 41-57.

Hatcher, P. J., Hulme, C., \& Snowling, M. J. (2004). Explicit phonological training combined with reading instruction helps young children at risk of reading failure. Journal of Child Psychology and Psychiatry, 45, $338-358$.

Haynes, C., \& Naidoo, S. (1991). Clinics in developmental medicine: Vol.
119. Children with specific speech and language impairment. London: MacKeith Press.

Hendriks, A., \& Kolk, H. (1997). Strategic control in developmental dyslexia. Cognitive Neuropsychology, 14, 321-366.

Hulme, C., \& Snowling, M. J. (1992). Deficits in output phonology: An explanation of reading failure? Cognitive Neuropsychology, 9, 47-72.

Hynd, G. W., Semrud-Clikeman, M., Lorys, A. R., Novey, E. S., \& Eliopulos, D. (1990). Brain morphology in developmental dyslexia and attention deficit disorder/hyperactivity. Archives of Neurology, 47, 919 926

Jackson, N. E., \& Coltheart, M. (2001). Routes to reading success and failure. New York: Psychology Press.

Jackson, T., \& Plante, E. (1996). Gyral morphology in the posterior Sylvian region in families affected by developmental language disorder. Neuropsychology Review, 6, 81-94.

Jernigan, T., Hesselink, J. R., Sowell, E., \& Tallal, P. (1991). Cerebral structure on magnetic resonance imaging in language- and learningimpaired children. Archives of Neurology, 48, 539-545.

Joanisse, M. F., Manis, F. R., Keating, P., \& Seidenberg, M. S. (2000) Language deficits in dyslexic children: Speech perception, phonology, and morphology. Journal of Experimental Child Psychology, 77, 30-60.

Joffe, V. L. (1998). Rhyming and related skills in children with specific language impairment. Cahiers de Psychologie Cognitive/Current Psychology of Cognition, 17, 479-512.

Johnson, D. J., \& Myklebust, H. R. (1967). Learning disabilities: Educational principles and practice. New York: Grune \& Stratton.

Kamhi, A. G., \& Catts, H. W. (1986). Toward an understanding of developmental language and reading disorders. Journal of Speech and Hearing Disorders, 51, 337-347.

Kemp, N., \& Bryant, P. (2003). Do bees buzz? Rule-based and frequencybased knowledge in learning to spell plural -s. Child Development, 74, 63-74.

King, R. R., Jones, C., \& Lasky, E. (1982). In retrospect: A fifteen year follow-up report of speech-language disordered children. Language, Speech and Hearing Services in Schools, 13, 24-32.

Kintsch, W. (1998). Comprehension: A paradigm for cognition. New York: Cambridge University Press.

Klingberg, T., Hedehus, M., Temple, E., Salz, T., Gabrieli, J. D. E., Moseley, M. E., \& Poldrack, R. A. (2000). Microstructure of temporoparietal white matter as a basis for reading ability: Evidence from diffusion tensor magnetic resonance imaging. Neuron, 25, 493-500.

Kushch, A., Gross-Glenn, K., Jallad, B., Lubs, H., Rabin, M., Feldman, E., \& Duara, R. (1993). Temporal lobe surface area measurements on MRI in normal and dyslexic readers. Neuropsychologia, 31, 811-821.

Laing, E., \& Hulme, C. (1999). Phonological and semantic processes influence beginning readers' ability to learn to read words. Journal of Experimental Child Psychology, 73, 183-207.

Landau, W. M., Goldstein, R., \& Kleffner, R. (1960). Congenital aphasia: A clinicopathologic study. Neurology, 10, 915-921.

Larrivee, L. S., \& Catts, H. W. (1999). Early reading achievement in children with expressive phonological disorders. American Journal of Speech-Language Pathology, 8, 118-128.

Leach, J. M., Scarborough, H. S., \& Rescorla, L. (2003). Late-emerging reading disabilities. Journal of Educational Psychology, 95, 211-224.

Lefly, D. L., \& Pennington, B. F. (1996). Longitudinal study of children at high family risk for dyslexia: The first two years. In M. L. Rice (Ed.), Toward a genetics of language (pp. 49-75). Hillsdale, NJ: Erlbaum.

Leitão, S., Hogben, J., \& Fletcher, J. (1997). Phonological processing skills in speech and language impaired children. European Journal of Disorders of Communication, 32, 73-93.

Leonard, C. M., Eckert, M. A., Lombardino, L. J., Oakland, T., Kranzler, J., Mohr, C. M., et al. (2001). Anatomical risk factors for phonological dyslexia. Cerebral Cortex, 11, 148-157.

Leonard, C. M., Lombardino, L. J., Walsh, K., Eckert, M. A., Mockler, 
J. L., Rowe, L. A., et al. (2002). Anatomical risk factors that distinguish dyslexia from SLI predict reading skill in normal children. Journal of Communication Disorders, 35, 501-531.

Leonard, C. M., Voeller, K. K., Lombardino, L. J., Morris, M. K., Hynd, G. W., Alexander, A. W., et al. (1993). Anomalous cerebral structure in dyslexia revealed with magnetic resonance imaging. Archives of Neurology, 50, 461-469.

Leonard, L. B. (1998). Children with specific language impairment. Cambridge, MA: MIT Press.

Lewis, B. A. (1992). Pedigree analysis of children with phonology disorders. Journal of Learning Disabilities, 25, 586-597.

Locke, J. L., Hodgson, J., Macaruso, P., Roberts, J., Lambrecht-Smith, S., \& Guttentag, C. (1997). The development of developmental dyslexia. In C. Hulme \& M. Snowling (Eds.), Dyslexia: Biology, cognition and intervention (pp. 72-96). London: Whurr.

Lum, C., Cox, R., Kilgour, J., Morris, J., Snowling, M., Haywood, S., et al. (2000). PATSy: Patient database for research and training. Available at http://www.patsy.ac.uk

Lundberg, I., Olofsson, A., \& Wall, S. (1980). Reading and spelling skills in the first school years predicted from phonemic awareness skills in kindergarten. Scandinavian Journal of Psychology, 121, 159-173.

Lyon, G. R. (1995). Towards a definition of dyslexia. Annals of Dyslexia, 45, 3-27.

Lyytinen, P., Poikkeus, A. M., Laakso, M. L., Eklund, K., \& Lyytinen, H. (2001). Language development and symbolic play in children with and without familial risk for dyslexia. Journal of Speech, Language, and Hearing Research, 44, 873-885.

Magnusson, E., \& Naucler, K. (1990). Reading and spelling in language disordered children - Linguistic and metalinguistic pre-requisites: A report on a longitudinal study. Clinical Linguistics and Phonetics, 4, $49-61$.

Manis, F. R., \& Bailey, C. E. (2001, April). Longitudinal study of dyslexic subgroups. Paper presented at the Fourth International Conference of the British Dyslexia Association, York, England.

Manis, F. R., Seidenberg, M. S., Doi, L. M., McBride-Chang, C., \& Petersen, A. (1996). On the bases of two subtypes of development dyslexia. Cognition, 58, 157-195.

Marlow, A. J., Fisher, S. E., Francks, C., MacPhie, I. L., Cherny, S. S., Richardson, A. J., et al. (2003). Use of multivariate linkage analysis for dissection of a complex trait. American Journal of Human Genetics, 72, 561-570.

Marshall, C. M., Snowling, M. J., \& Bailey, P. J. (2001). Rapid auditory processing and phonological processing in normal readers and readers with dyslexia. Journal of Speech, Language, and Hearing Research, 44, 925-940.

McArthur, G. M., \& Bishop, D. V. M. (2001). Auditory perceptual processing in people with reading and oral language impairments: Current issues and recommendations. Dyslexia, 7, 150-170.

McArthur, G. M., Hogben, J. H., Edwards, V. T., Heath, S. M., \& Mengler, E. D. (2000). On the "specifics" of specific reading disability and specific language impairment. Journal of Child Psychology and Psychiatry, 41, 869-874.

Merzenich, M. (2001). Cortical plasticity contributing to child development. In J. L. McClelland \& R. S. Siegler (Eds.), Mechanisms of cognitive development: Behavioral and neural mechanisms (pp. 67-95). Mahwah, NJ: Erlbaum.

Metsala, J. L., Stanovich, K. E., \& Brown, G. D. A. (1998). Regularity effects and the phonological deficit model of reading disabilities: A meta-analytic review. Journal of Educational Psychology, 90, 279-293.

Montgomery, J. W., \& Leonard, L. B. (1998). Real-time inflectional processing by children with specific language impairment: Effects of phonetic substance. Journal of Speech, Language, and Hearing Research, 41, 1432-1443.

Morais, J., Cary, L., Alegria, J., \& Bertelson, P. (1979). Does awareness of speech as a sequence of phones arise spontaneously? Cognition, 7, 323-331.

Morris, R. D., Stuebing, K. K., Fletcher, J. M., Shaywitz, S. E., Lyon, G. R., Shankweiler, D. P., et al. (1998). Subtypes of reading disability: Variability around a phonological core. Journal of Educational Psychology, 90, 347-373.

Morton, J., \& Frith, U. (1995). Causal modeling: A structural approach to developmental psychopathology. In D. Cicchetti \& D. J. Cohen (Eds.), Developmental psychopathology (Vol. 2, pp. 357-390). New York: Wiley.

Murphy, L., \& Pollatsek, A. (1994). Developmental dyslexia: Heterogeneity without discrete subgroups. Annals of Dyslexia, 44, 120-146.

Naidoo, S. (1972). Specific dyslexia. London: Pitman.

Nathan, L., Stackhouse, J., Goulandris, N., \& Snowling, M. J. (2004). The development of early literacy skills and children with speech difficulties: A test of the "critical age hypothesis." Journal of Speech, Language, and Hearing Research, 47, 337-391.

Nation, K., Adams, J. W., Bowyer-Crane, C. A., \& Snowling, M. J. (1999). Working memory deficits in poor comprehenders reflect underlying language impairments. Journal of Experimental Child Psychology, 73, $139-158$.

Nation, K., Clarke, P., Marshall, C. M., \& Durand, M. (2004). Hidden language impairments in children: Parallels between poor reading comprehension and specific language impairment? Journal of Speech, Language, and Hearing Research, 47, 199-211.

Nation, K., Clarke, P., \& Snowling, M. J. (2002). General cognitive ability in children with reading comprehension difficulties. British Journal of Educational Psychology, 72, 549-560.

Nation, K., Marshall, C., \& Snowling, M. J. (2001). Phonological and semantic contributions to children's picture naming skills: Evidence from children with developmental reading disorder. Language and Cognitive Processes, 16, 241-259.

Nation, K., \& Snowling, M. (1997). Assessing reading difficulties: The validity and utility of current measures of reading skill. British Journal of Educational Psychology, 67, 359-370.

Nation, K., \& Snowling, M. J. (1998a). Individual differences in contextual facilitation: Evidence from dyslexia and poor reading comprehension. Child Development, 69, 996-1011.

Nation, K., \& Snowling, M. J. (1998b). Semantic processing and the development of word recognition skills: Evidence from children with reading comprehension difficulties. Journal of Memory and Language, $39,85-101$

Nation, K., \& Snowling, M. J. (1999). Developmental differences in sensitivity to semantic relations among good and poor comprehenders: Evidence from semantic priming. Cognition, 70, B1-B13.

Naucler, K., \& Magnusson, E. (2002). How do preschool language problems affect language abilities in adolescence? In F. Windsor, L. Kelly, \& N. Hewlett (Eds.), Investigations in clinical phonetics and linguistics (pp. 99-114). Mahwah, NJ: Erlbaum.

Neale, M. D. (1997). Neale Analysis of Reading Ability II: Second Revised British Edition. Windsor, England: NFER-Nelson.

Newbury, D. F., Bonora, E., Lamb, J. A., Fisher, S. E., Lai, C. S. L., Baird, G., et al. (2002). FOXP2 is not a major susceptibility gene for autism or specific language impairment. American Journal of Human Genetics, $70,1318-1327$.

Nicolson, R. I., Fawcett, A. J., \& Dean, P. (2001). Developmental dyslexia: The cerebellar deficit hypothesis. Trends in Neurological Sciences, 24, $508-511$.

Norbury, C. F., Bishop, D. V. M., \& Briscoe, J. (2001). Production of verb morphology: A comparison of SLI and moderate hearing impairment. Journal of Speech, Language, and Hearing Research, 44, 165-178.

Norbury, C., \& Chiat, S. (2000). Semantic intervention to support word recognition: A single-case study. Child Language Teaching and Therapy, 16, 141-163. 
Nunes, T., Bryant, P., \& Bindman, M. (1997). Morphological spelling strategies: Developmental stages and processes. Developmental Psychology, 33, 637-649.

Oakhill, J. V. (1993). Children's difficulties in text comprehension. Educational Psychology Review, 5, 223-237.

Olson, R., \& Datta, H. (2002). Visual-temporal processing in readingdisabled and normal twins. Reading and Writing, 15, 127-149.

Olson, R. K., Datta, H. J. G., \& DeFries, J. C. (1999). A behavior-genetic analysis of reading disabilities and component processes. In R. M. Klein $\&$ P. McMullen (Eds.), Converging methods for understanding reading and dyslexia (pp. 133-152). Cambridge, MA: MIT Press.

Olson, R., Wise, B., Conners, F., Rack, J., \& Fulker, D. (1989). Specific deficits in component reading and language skills: Genetic and environmental influences. Journal of Learning Disabilities, 22, 339-349.

Olson, R. K., Wise, B., Johnson, M., \& Ring, J. (1997). The etiology and remediation of phonologically based word recognition and spelling disabilities: Are phonological deficits the "hole" story? In B. Blachman (Ed.), Foundations of reading acquisition (pp. 305-326). Mahwah, NJ: Erlbaum.

Paulesu, E., Frith, U., Snowling, M. J., Gallagher, A., Morton, J., Frackowiak, R. S. J., \& Frith, C. D. (1996). Is developmental dyslexia a disconnection syndrome? Evidence from PET scanning. Brain, 119, 143-157.

Pennington, B. F. (2002). The development of psychopathology: Nature and nurture. New York: Guilford Press

Pennington, B. F., \& Lefly, D. L. (2001). Early reading development in children at family risk for dyslexia. Child Development, 72, 816-833.

Perera, K. (1984). Children's writing and reading. Oxford, England: Blackwell.

Plante, E., Swisher, L., Vance, R., \& Rapcsak, S. (1991). MRI findings in boys with specific language impairment. Brain and Language, 41, $52-66$.

Plaut, D. C. (1997). Structure and function in the lexical system: Insights from distributed models of word reading and lexical decision. Language and Cognitive Processes, 12, 765-805.

Plaut, D. C., McClelland, J. L., Seidenberg, M. S., \& Patterson, K. (1996). Understanding normal and impaired word reading: Computational principles in quasi-regular domains. Psychological Review, 103, 56-115.

Preis, S., Jaencke, L., Schittler, P., Huang, Y., \& Steinmetz, H. (1998). Normal intrasylvian anatomical asymmetry in children with developmental language disorder. Neuropsychologia, 36, 849-855.

Rack, J. P., Snowling, M. J., \& Olson, R. K. (1992). The nonword reading deficit in developmental dyslexia. Reading Research Quarterly, 27, $29-53$.

Raitano, N. A., Pennington, B. F., Tunick, R. A., Boada, R., \& Shriberg, L. (2004). Pre-literacy skills of subgroups of children with phonological disorder. Journal of Child Psychology and Psychiatry, 45, 821-835.

Ramus, F. (2003). Developmental dyslexia: Specific phonological deficit or general sensorimotor dysfunction? Current Opinion in Neurobiology, $13,212-218$.

Ramus, F., Rosen, S., Dakin, S. C., Day, B. L., Castellote, J. M., White, S., \& Frith, U. (2003). Theories of developmental dyslexia: Insights from a multiple case study of dyslexic adults. Brain, 126, 841-865.

Rapin, I., \& Allen, D. (1983). Developmental language disorders: Nosologic considerations. In U. Kirk (Ed.), Neuropsychology of language, reading, and spelling (pp. 155-184). New York: Academic Press.

Raskind, W. H., Hsu, L., Berninger, V. W., Thomson, J. B., \& Wijsman, E. M. (2000). Family aggregation of dyslexia phenotypes. Behavior Genetics, 30, 385-396.

Read, C., Zhang, Y., Nie, H., \& Ding, B. (1986). The ability to manipulate speech sounds depends on alphabetic writing. Cognition, 24, 31-44.

Rego, L. L., \& Bryant, P. E. (1993). The connection between phonological, syntactic and semantic skills and children's reading and spelling. European Journal of Psychology of Education, 8, 235-246.
Reiss, A. L., \& Denckla, M. B. (1996). The contribution of neuroimaging: Fragile X syndrome, Turner syndrome, and neurofibromatosis I. In G. R. Lyon \& J. M. Rumsey (Eds.), Neuroimaging (pp. 147-168). Baltimore: Brooks.

Rice, M. L. (2000). Grammatical symptoms of specific language impairment. In D. V. M. Bishop \& L. B. Leonard (Eds.), Speech and language impairments in children: Causes, characteristics, intervention and outcome (pp. 17-34). Hove, England: Psychology Press.

Rice, M. L., \& Oetting, J. B. (1993). Morphological deficits of children with SLI: Evaluation of number marking and agreement. Journal of Speech and Hearing Research, 36, 1249-1257.

Rice, M. L., Wexler, K., \& Redmond, S. M. (1999). Grammaticality judgments of an extended optional infinitive grammar: Evidence from English-speaking children with specific language impairment. Journal of Speech, Language, and Hearing Research, 42, 943-961.

Richards, T. L., Corina, D., Serafini, S., Steury, K., Echelard, D. R., Dager, S. R., et al. (2000). The effects of a phonologically-driven treatment for dyslexia on lactate levels as measured by proton MSI. American Journal of Neuroradiology, 21, 916-922.

Rosen, G. D., Sherman, G. F., \& Galaburda, A. M. (1993). Dyslexia and brain pathology: Experimental animal models. In A. M. Galaburda (Ed.), Dyslexia and development: Neurobiological aspects of extra-ordinary brains (pp. 89-111). Cambridge, MA: Harvard University Press.

Rosen, S. (2003). Auditory processing in dyslexia and specific language impairment. Is there a deficit? What is its nature? Does it explain anything? Journal of Phonetics, 31, 509-527.

Rumsey, J. M., Donohue, B. C., Brady, D. R., Nace, K., Giedd, J. N., \& Andreason, P. (1997). A magnetic resonance imaging study of planum temporale asymmetry in men with developmental dyslexia. Archives of Neurology, 54, 1481-1489.

Rutter, M., \& Maughan, B. (2002). School effectiveness findings 1979 2002. Journal of School Psychology, 40, 451-475.

Rutter, M., \& Yule, W. (1970). Neurological aspects of intellectual retardation and specific reading retardation. In M. Rutter, J. Tizard, \& K Whitmore (Eds.), Education, health and behavior (pp. 54-74). London: Longman.

Scarborough, H. S. (1990). Very early language deficits in dyslexic children. Child Development, 61, 1728-1743.

Scarborough, H. S., \& Dobrich, W. (1990). Development of children with early language delay. Journal of Speech and Hearing Research, 33, $70-83$.

Seidenberg, M. (1992). Dyslexia in a computational model of word recognition in reading. In P. B. Gough, L. Ehri, \& R. Treiman (Eds.), Reading acquisition (pp. 243-273). London: Erlbaum.

Seidenberg, M. S., \& McClelland, J. (1989). A distributed, developmental model of word recognition. Psychological Review, 96, 523-568.

Semel, E. M., Wiig, E. H., \& Secord, W. (1987). Clinical Evaluation of Language Fundamentals-Revised. San Antonio, TX: Psychological Corporation.

Seymour, P. H. K. (1986). A cognitive analysis of dyslexia. London: Routledge \& Kegan Paul.

Shankweiler, D., \& Crain, S. (1986). Language mechanisms and reading disorder: A modular approach. Cognition, 24, 139-168.

Shankweiler, D., Lundquist, E., Katz, L., Stuebing, K. K., Fletcher, J. M., Brady, S., \& Stein, J. F. (1999). Comprehension and decoding: Patterns of association in children with reading difficulties. Scientific Studies of Reading, 3, 69-94.

Share, D. L. (1995). Phonological recoding and self-teaching: Sine qua non of reading acquisition. Cognition, 55, 151-218.

Share, D. L. (1999). Phonological recoding and orthographic learning: A direct test of the self-teaching hypothesis. Journal of Experimental Child Psychology, 72, 95-129.

Share, D. L., \& Leikin, M. (2004). Language impairment at school entry 
and later reading disability: Connections at lexical versus supralexical levels of reading. Scientific Studies of Reading, 8, 87-110.

Share, D. L., \& Silva, P. A. (1987). Language deficits and specific reading retardation: Cause or effect? British Journal of Disorders of Communication, 22, 219-226.

Shatil, E., \& Share, D. L. (2003). Cognitive antecedents of early reading ability: A test of the modularity hypothesis. Journal of Experimental Child Psychology, 86, 1-31.

Shaywitz, B. A., Holford, T. R., Holahan, J. M., Fletcher, J. M., Steubing, K. K., Francis, D. J., et al. (1995). A Matthew effect for IQ but not for reading: Results from a longitudinal study. Reading Research Quarterly, 30, 894-906.

Shaywitz, B. A., Shaywitz, S. E., Pugh, K. R., Mencl, W. E., Fulbright, R. K., Skudlarski, P., et al. (2002). Disruption of posterior brain systems for reading in children with developmental dyslexia. Biological Psychiatry, 52, 101-110.

Shaywitz, S. E., Bennett, B. A., Fulbright, R., K., Skudlarski, P., Mencl, E., Constable, R. T., et al. (2003). Neural systems for compensation and persistence: Young adult outcome of childhood reading disability. Biological Psychiatry, 54, 25-33.

Shaywitz, S. E., Escobar, M. D., Shaywitz, B. A., Fletcher, J. M., \& Makuch, R. (1992). Evidence that dyslexia may represent the lower tail of a normal distribution of reading ability. New England Journal of Medicine, 326, 145-150.

SLI Consortium. (2002). A genome-wide scan identifies two novel loci involved in specific language impairment (SLI). American Journal of Human Genetics, 70, 384-398.

SLI Consortium. (2004). Highly significant linkage to SLI1 locus in an expanded sample of individuals affected by specific language impairment (SLI). American Journal of Human Genetics, 94, 1225-1238.

Snowling, M. J. (1981). Phonemic deficits in developmental dyslexia. Psychological Research, 43, 219-234.

Snowling, M. J. (1987). Dyslexia: A cognitive developmental perspective. Oxford, England: Blackwell.

Snowling, M. J. (2000). Dyslexia (2nd ed.). Oxford, England: Blackwell.

Snowling, M., Bishop, D. V. M., \& Stothard, S. E. (2000). Is pre-school language impairment a risk factor for dyslexia in adolescence? Journal of Child Psychology and Psychiatry, 41, 587-600.

Snowling, M. J., Gallagher, A., \& Frith, U. (2003). Family risk of dyslexia is continuous: Individual differences in the precursors of reading skill. Child Development, 74, 358-373.

Snowling, M. J., Goulandris, N., Bowlby, M., \& Howell, P. (1986). Segmentation and speech perception in relation to reading skill: A developmental analysis. Journal of Experimental Child Psychology, 41, 489-507.

Snowling, M. J., Goulandris, N., \& Defty, N. (1998). Development and variation in developmental dyslexia. In C. Hulme \& M. Joshi (Eds.), Cognitive and linguistic bases of reading, writing and spelling (pp. 201-217). Mahwah, NJ: Erlbaum.

Snowling, M. J., \& Hulme, C. (1994). The development of phonological skills. Philosophical Transactions of the Royal Society, Series B, 346, 21-28.

Stackhouse, J., \& Snowling, M. J. (1992). Barriers to literacy development in two cases of developmental verbal dyspraxia. Cognitive Neuropsychology, 9, 273-299.

Stanovich, K. E. (1986). Matthew effects in reading: Some consequences of individual differences in the acquisition of literacy. Reading Research Quarterly, 21, 360-364.

Stanovich, K. E. (1994). Annotation: Does dyslexia exist? Journal of Child Psychology and Psychiatry, 35, 579-595.

Stanovich, K. E., \& Siegel, L. S. (1994). Phenotypic performance profile of reading-disabled children: A regression-based test of the phonologicalcore variable-difference model. Journal of Educational Psychology, 86, $24-53$.
Stanovich, K. E., Siegel, L. S., \& Gottardo, A. (1997). Progress in the search for dyslexia sub-types. In C. Hulme \& M. Snowling (Eds.), Dyslexia: Biology, cognition and intervention (pp. 108-130). London: Whurr.

Stark, R. E., Bernstein, L. E., Condino, R., Bender, M., Tallal, P., \& Catts, H. (1984). Four-year follow-up study of language impaired children. Annals of Dyslexia, 34, 49-68.

Stark, R. E., \& Tallal, P. (1988). Language, speech and reading disorders in children. Boston: Little, Brown.

Stein, J., \& Talcott, J. (1999). Impaired neuronal timing in developmental dyslexia-The magnocellular hypothesis. Dyslexia, 5, 59-77.

Stevenson, J. (1991). Which aspects of processing text mediate genetic effects? Reading and Writing, 3, 249-269.

Stevenson, J., Graham, P., Fredman, G., \& McLoughlin, V. (1987). A twin study of genetic influences on reading and spelling ability and disability. Journal of Child Psychology and Psychiatry, 28, 229-247.

Stothard, S., \& Hulme, C. (1995). A comparison of reading comprehension and decoding difficulties in children. Journal of Child Psychology and Psychiatry, 36, 399-408.

Stothard, S. E., Snowling, M. J., Bishop, D. V. M., Chipchase, B. B., \& Kaplan, C. A. (1998). Language impaired preschoolers: A follow-up into adolescence. Journal of Speech, Language, and Hearing Research, 41, 407-418.

Swan, D., \& Goswami, U. (1997a). Phonological awareness deficits in developmental dyslexia and the phonological representations hypothesis. Journal of Experimental Child Psychology, 60, 334-353.

Swan, D., \& Goswami, U. (1997b). Picture naming deficits in developmental dyslexia: The phonological representations hypothesis. Brain and Language, 56, 334-353.

Taipale, M., Kaminen, N., Nopola-Hemmi, J., Haltia, T., Myllyluoma, B., Lyytinen, H., et al. (2003). A candidate gene for developmental dyslexia encodes a nuclear tetratricopeptide repeat domain protein dynamically regulated in brain. Proceedings of the National Academy of Sciences, USA, 100, 11553-11558.

Talcott, J. B., Witton, C., McLean, M. F., Hansen, P. C., Rees, A., Green, G. G. R., et al. (2000). Dynamic sensory sensitivity and children's word decoding skills. Proceedings of the National Academy of Sciences, USA, 97, 2952-2957.

Tallal, P. (1975). Perceptual and linguistic factors in the language impairment of developmental dysphasics: An experimental investigation with the Token test. Cortex, 11, 196-205.

Tallal, P. (1980). Auditory temporal perception, phonics and reading disabilities in children. Brain and Language, 9, 182-198.

Tallal, P. (2000). Experimental studies of language learning impairments: From research to remediation. In D. V. M. Bishop \& L. B. Leonard (Eds.), Speech and language impairments in children: Causes, characteristics, intervention and outcome (pp. 131-155). Hove, England: Psychology Press.

Tallal, P., Allard, L., Miller, S., \& Curtiss, S. (1997). Academic outcomes of language impaired children. In C. Hulme \& M. Snowling (Eds.), Dyslexia: Biology, cognition and intervention (pp. 167-181). London: Whurr.

Tallal, P., \& Piercy, M. (1974). Developmental aphasia: Rate of auditory processing and selective impairment of consonant perception. Neuropsychologia, 12, 83-93.

Tallal, P., \& Stark, R. E. (1982). Perceptual/motor profiles of reading impaired children with or without concomitant oral language deficits. Annals of Dyslexia, 32, 163-176.

Tallal, P., Stark, R. E., Kallman, C., \& Mellits, D. (1980). Perceptual constancy for phonemic categories: A developmental study with normal and language impaired children. Applied Psycholinguistics, 1, 49-64.

Tallal, P., Townsend, J., Curtiss, S., \& Wulfeck, B. (1991). Phenotypic profiles of language-impaired children based on genetic/family history. Brain and Language, 41, 81-95. 
Taylor, H. G., Lean, D., \& Schwartz, S. (1989). Pseudoword repetition ability in learning-disabled children. Applied Psycholinguistics, 10, 203219.

Temple, E. (2002). Brain mechanisms in normal and dyslexic readers. Current Opinion in Neurobiology, 12, 178-183.

Temple, E., Poldrack, R. A., Protopapas, S., Nagarajan, T., Salz, P., Tallal, P., et al. (2000). Disruption of the neural response to rapid acoustic stimuli in dyslexia: Evidence from functional MRI. Proceedings of the National Academy of Sciences, USA, 97, 13907-13912.

Temple, E., Poldrack, R. A., Salidis, J., Deutsch, G. K., Tallal, P., Merzenich, M. M., et al. (2001). Disrupted neural responses to phonological and orthographic processing in dyslexic children: An fMRI study. NeuroReport, 12, 299-307.

Tomblin, J. B., Freese, P. R., \& Records, N. L. (1992). Diagnosing specific language impairment in adults for the purpose of pedigree analysis. Journal of Speech and Hearing Research, 35, 832-843.

Tomblin, J. B., Records, N. L., Buckwalter, P., Zhang, X., Smith, E., \& O'Brien, M. (1997). Prevalence of specific language impairment in kindergarten children. Journal of Speech and Hearing Research, 40, $1245-1260$

Tomblin, J. B., Records, N., \& Zhang, X. (1996). A system for the diagnosis of specific language impairment in kindergarten children. Journal of Speech and Hearing Research, 39, 1284-1294.

Torgesen, J. K. (2000). Individual differences in response to early interventions in reading: The lingering problem of treatment resisters. Learning Disabilities Research and Practice, 15, 55-64.

Trehub, S. E., \& Henderson, J. L. (1996). Temporal resolution in infancy and subsequent language development. Journal of Speech and Hearing Research, 39, 1315-1320.

Treiman, R., \& Cassar, M. (1996). Effects of morphology on children's spelling of final consonant clusters. Journal of Experimental Child Psychology, 63, 141-170.

Tunick, R. A., \& Pennington, B. F. (2002). The etiological relationship between reading disability and phonological disorder. Annals of Dyslexia, 52, 75-95.

Tunmer, W. E., \& Chapman, J. W. (1998). Language prediction skills, phonological recoding ability and beginning reading. In M. Joshi \& C. Hulme (Eds.), Reading and spelling: Development and disorders (pp. 33-67). Hillsdale, NJ: Erlbaum.

Udwin, O., \& Dennis, J. (1995). Psychological and behavioral phenotypes in genetically determined syndromes: A review of research findings. In G. O'Brien \& W. Yule (Eds.), Behavioral phenotypes (pp. 90-208). London: MacKeith Press.

Van Daal, V., \& Van der Leij, A. (1999). Developmental dyslexia: Related to specific or general deficits? Annals of Dyslexia, 49, 71-104.

Van der Bon, W. H., \& Van der Pijl, J. M. L. (1997). Effects of word length and wordlikeness on pseudoword repetition by poor and normal readers. Applied Psycholinguistics, 18, 101-114.

Van der Lely, H. K. J. (1996). Specifically language impaired and normally developing children: Verbal passive vs. adjectival passive sentence interpretation. Lingua, 98, 243-272.

Van der Lely, H., \& Stollwerck, L. (1997). Binding theory and grammatical specific language impairment in children. Cognition, 62, 245-290.

Van der Lely, H. K. J., \& Ullman, M. T. (2001). Past tense morphology in specifically language impaired and normally developing children. Language and Cognitive Processes, 16, 177-217.

Vellutino, F. R. (1979). Dyslexia: Research and theory. Cambridge, MA: MIT Press.

Vellutino, F. R. (1987, March). Dyslexia. Scientific American, 256, 34-41. Vellutino, F. R., Scanlon, D. M., Sipay, E. R., Small, S. G., Pratt, A., Chen, R., \& Denckla, M. B. (1996). Cognitive profiles of difficult-to-remediate and readily remediated poor readers: Early intervention as a vehicle for distinguishing between cognitive and experiential deficits as basic causes of specific reading disability. Journal of Educational Psychology, $88,601-638$.

Vellutino, F. R., Scanlon, D. M., \& Spearing, D. (1995). Semantic and phonological coding in poor and normal readers. Journal of Experimental Child Psychology, 59, 76-123.

Viholainen, H., Ahonen, T., Cantell, M., Lyytinen, P., \& Lyytinen, H. (2002). Development of early motor skills and language in children at risk for familial dyslexia. Developmental Medicine and Child Neurology, 44, 761-769.

Wagner, R. K., Torgesen, J. K., \& Rashotte, C. A. (1994). Development of reading-related phonological processing abilities: Evidence of bidirectional causality from a latent variable longitudinal study. Developmental Psychology, 30, 73-87.

Watkins, K. E., Vargha-Khadem, F., Ashburner, J., Passingham, R. E., Connelly, A., Friston, K. J., et al. (2002). MRI analysis of an inherited speech and language disorder: Structural brain abnormalities. Brain, 125, 465-478.

Whitehurst, G. J., \& Fischel, J. E. (2000). Reading and language impairments in conditions of poverty. In D. V. M. Bishop \& L. B. Leonard (Eds.), Speech and language impairments in children: Causes, characteristics, intervention and outcome (pp. 53-72). Hove, England: Psychology Press.

Whitehurst, G., \& Lonigan, C. J. (1998). Child development and emergent literacy. Child Development, 69, 848-872.

Williams, M. J., Stuart, G. W., Castles, A., \& McAnally, K. I. (2003). Contrast sensitivity in subgroups of developmental dyslexia. Vision Research, 43, 467-477.

Wimmer, H., Landerl, K., Linortner, R., \& Hummer, P. (1991). The relationship of phonemic awareness to reading acquisition: More consequence than precondition but still important. Cognition, 40, 219-249.

Wimmer, H., Mayringer, H., \& Landerl, K. (1998). Poor reading: A deficit in skill automatization or a phonologic deficit? Scientific Studies of Reading, 2, 321-340.

Winne, P. H., Graham, L., \& Prock, L. (1993). A model of poor readers' text-based inferencing: Effects of explanatory feedback. Reading Research Quarterly, 28, 53-66.

Wise, B. W., Ring, J., \& Olson, R. K. (1999). Training phonological awareness with and without explicit attention to articulation. Journal of Experimental Child Psychology, 72, 271-304.

Witton, C., Stein, J. F., Stoodley, C. J., Rosner, B. S., \& Talcott, J. B. (2002). Separate influences of acoustic AM and FM sensitivity on the phonological decoding skills of impaired and normal readers. Journal of Cognitive Neuroscience, 14, 866-874.

Witton, C., Talcott, J. B., Hansen, P. C., Richardson, A. J., Griffiths, T. D., Rees, A., et al. (1998). Sensitivity to dynamic auditory and visual stimuli predicts nonword reading ability in both dyslexic and normal readers. Current Biology, 8, 791-797.

Wolff, P. H. (1999). A candidate phenotype for familial dyslexia. European Child and Adolescent Psychiatry, 8(Suppl. 3), III/21-III/27.

World Health Organization. (1993). The ICD-10 classification for mental and behavioral disorders: Diagnostic criteria for research. Geneva, Switzerland: Author.

Worster-Drought, C. (1943). Congenital auditory imperception (congenital word-deafness) and its relation to idioglossia and allied speech defects. Medical Press and Circular, 210, 411-417.

Yuill, N., \& Oakhill, J. (1991). Children's problems in text comprehension. Cambridge, England: Cambridge University Press.

Received July 30, 2003

Revision received February 20, 2004

Accepted April 26, 2004 